Pesq. Vet. Bras. 37(7):759-772, julho 2017

DOI: $10.1590 / \mathrm{S} 0100-736 \mathrm{X} 2017000700018$

\title{
Ultrassonografia modo B e Doppler na avaliação renal de cães submetidos à tomografia computadorizada após administração intravenosa de diferentes meios de contraste iodado ${ }^{1}$
}

\author{
Cláudia Matsunaga Martín²*, Marcia Mery Kogika3 ${ }^{3}$, Samantha Ive Miyashiro ${ }^{4}$ \\ e Ana Carolina Brandão de Campos Fonseca-Pinto ${ }^{5}$
}

\begin{abstract}
Martín C.M., Kogika M.M., Miyashiro S.I. \& Fonseca-Pinto A.C.B.C. 2017. [B-mode and Doppler ultrasonography in the renal evaluation of dogs undergoing computed tomography after intravenous administration of different iodinated contrast media.] Ultrassonografia modo B e Doppler na avaliação renal de cães submetidos à tomografia computadorizada após administração intravenosa de diferentes meios de contraste iodado. Pesquisa Veterinária Brasileira 37(7):759-772. Programa de Pós-Graduação em Clínica Cirúrgica Veterinária, Faculdade de Medicina Veterinária e Zootecnia, Universidade de São Paulo, Av. Prof. Orlando Marques de Paiva 87, Cidade Universitária, São Paulo, SP 05508-270, Brazil. E-mail: cmmartin@uol.com.br

Contrast-induced nephropathy (CIN) is an acute disease, secondary to intravascular administration of iodinated contrast media (ICM). The most important mechanisms of this nephropathy are intrarenal prolonged vasoconstriction, medular hypoxia, and ischemia associated with renal tubular damage due to contrast cytotoxicity. Owing to the limited information available in veterinary literature regarding these mechanisms this study aims to compare the renal effects of intravenous administration of two nonionic ICM of different osmolarities in groups of dogs with risk factors for CIN development, by using a B-mode, color, power- and pulsed-wave Doppler ultrasonography, and other laboratory tests, in order to indirectly estimate the nephrotoxic potential of each contrast. The following two groups were established according to the nonionic ICM used: the GIH group [11 dogs administered iohexol (low osmolarity)] and the GID group [seven dogs administered iodixanol (iso-osmolarity)]. Both the groups were administered the same dose $(600 \mathrm{mgI} / \mathrm{kg} / \mathrm{IV})$. The following renal aspects were evaluated before administration of ICM (baseline) and after $1 \mathrm{~h} 30 \mathrm{~min}, 24 \mathrm{~h}$, and $48 \mathrm{~h}$ : renal morphometry (length and volume), renal morphology, cortical echogenicity, renal perfusion, and intrarenal vascular resistance (resistive and pulsatility indices); in addition, urinalysis was performed, and urinary gamma-glutamyl transferase:creatinine ratio (GGT:C), urinary protein:creatinine ratio (UPC), and serum creatinine were also measured. Both groups showed similar characteristics with respect to the length, volume, UPC ratio, urinalysis, and serum creatinine levels. No similarity was observed with respect to the pulsatility index (PI) in both the groups and there were no significant differences between baseline and $1 \mathrm{~h} 30 \mathrm{~min}, 24 \mathrm{~h}$ and $48 \mathrm{~h}$ time points. With respect to the IR and urinary GGT:C, both groups showed no similarity, and significant increases were
\end{abstract}

\footnotetext{
${ }^{1}$ Recebido em 13 de maio de 2016.

Aceito para publicação em 6 de dezembro de 2016.

Parte da tese de doutorado do primeiro autor.

${ }^{2}$ Doutora pelo Programa de Pós-Graduação em Clínica Cirúrgica Veterinária, Faculdade de Medicina Veterinária e Zootecnia (FMVZ), Universidade de São Paulo (USP), Cidade Universitária, Av. Prof. Orlando Marques de Paiva 87, São Paulo, SP 05508-270, Brasil. *Autor para correspondência: cmmartin@uol.com.br
}

\footnotetext{
${ }^{3}$ Docente, Departamento de Clínica Médica, Faculdade de Medicina Veterinária e Zootecnia (FMVZ), Universidade de São Paulo (USP), Av. Prof. Orlando Marques de Paiva 87, Cidade Universitária, SP 05508-270, Brasil.

${ }^{4}$ Departamento de Clínica Médica,Faculdade de Medicina Veterinária e Zootecnia (FMVZ), Universidade de São Paulo (USP), Av. Prof. Orlando Marques de Paiva 87, Cidade Universitária, SP 05508-270, Brasil.

${ }^{5}$ Docente, Departamento de Cirurgia, FMVZ-USP, Av. Prof. Orlando Marques de Paiva 87, Cidade Universitária, SP 05508-270, Brasil.
} 
observed in the resistive index (RI) and urinary GGT:C only in the GIH group, 1h30min after contrast administration. In conclusion, RI can be used to monitor intrarenal hemodynamics, and along with the urinary GGT:C, revealed that iohexol had higher nephrotoxic potential than iodixanol. Thus, iodixanol is considered a favorable option for dogs with risk factors for CIN development.

INDEX TERMS: B-mode, Doppler ultrasonography, kidneys, intravenous iodinated contrast media, nephrotoxicity, radiocontrast media, osmolarity, dog.

RESUMO.- A nefropatia induzida por contraste (NIC) é uma doença de caráter agudo, secundária à administração intravascular de meios de contraste iodado (MCI). Dentre os mecanismos fisiopatológicos desta enfermidade destacam-se a vasoconstrição intrarrenal prolongada, consequente redução da perfusão renal, hipóxia e isquemia medulares, associada ao dano tubular renal devido à citotoxicidade do contraste. Frente à existência de poucas informações relacionadas a estes mecanismos na literatura médico-veterinária, objetivaram-se comparar os efeitos renais da administração intravenosa de MCI não iônicos de diferentes osmolaridades, em grupos de cães com fatores de risco para o desenvolvimento da NIC, por meio das avaliações ultrassonográficas modo B, Doppler colorido, de amplitude e pulsado, pareada aos exames laboratoriais, a fim de estimar indiretamente o potencial nefrotóxico de cada contraste. Constituíram-se dois grupos de acordo com o MCI utilizado: o grupo GIH [11 cães receberam iohexol (baixa osmolaridade)] e o grupo GID [sete cães receberam iodixanol (isosmolar)]. Administrou-se a dose de $600 \mathrm{mgl} / \mathrm{kg} / \mathrm{IV}$ em ambos. Avaliaram-se os seguintes aspectos renais antes da administração do MCI (momento basal) e após 1h30min, 24 horas e 48 horas: morfometria (comprimento e volume), morfologia, ecogenicidade cortical e perfusão renais e resistência vascular intrarrenal (índices hemodinâmicos de resistividade e pulsatilidade). Realizou-se ainda exame de urina e se mensuraram as razões gama-glutamil transferase:creatinina (GGT:C) e proteína:creatinina (RPC) urinárias e a concentração sérica de creatinina. Os grupos apresentaram comportamentos similares para comprimento, volume, RPC, exame de urina e creatinina sérica. Em relação ao índice de pulsatilidade (IP), os grupos apresentaram comportamentos não similares, mas sem diferenças significantes entre o momento basal e os demais. Para o índice de resistividade (IR) e a razão GGT:C urinária, os grupos revelaram comportamentos não similares e se constataram aumentos significantes do IR e da razão GGT:C urinária no período de $1 \mathrm{~h} 30 \mathrm{~min}$ após a administração do contraste, somente para o grupo que recebeu iohexol. Concluiu-se que o IR pode ser utilizado para monitorar a hemodinâmica intrarrenal, visto que junto com a razão GGT:C urinária, demonstrou a existência de maior potencial nefrotóxico do iohexol, quando comparado ao iodixanol. Dessa forma, considera-se o uso do iodixanol, opção favorável para cães com fatores de risco para o desenvolvimento da NIC.

TERMOS DE INDEXAÇÃO: B-mode, ultrassonografia Doppler, rins, meios de contraste iodado intravenosa, nefrotoxicidade, contraste radiológico, osmolaridade, cão.

\section{INTRODUÇÃO}

Meios de contraste iodado (MCI) são substâncias capazes de promover a distinção de estruturas anatômicas com opacidades similares em exames radiológicos (Thomsen et al. 2014b). Após a administração intravascular, 99\% de sua eliminação ocorre por via renal, por meio da filtração glomerular, sem reabsorção tubular (Morcos \& Thomsen 2001, Santos et al. 2009). A excreção contínua do MCI do plasma para a urina é o princípio utilizado nos exames de urografia excretora que permite avaliar qualitativamente a função renal e aspectos anatomopatológicos do sistema urinário (Seiler, 2013). Sob o ponto de vista da tomografia computadorizada (TC), a difusão vascular do MCI após a administração intravenosa possibilita o estudo da vascularização propriamente dita, ou seja, da perfusão dos órgãos e o realce de lesões tumorais (Thomsen et al. 2014a).

Com o incremento dos exames de TC em pequenos animais, houve uma intensificação no uso intravenoso dos contrastes iodados (Pollard et al. 2008a,b). No entanto, como todo xenobiótico, essas substâncias não são inócuas. A estrutura química relaciona-se com a toxicidade e a eliminação. Já as propriedades físicas de ionicidade, osmolaridade, viscosidade e densidade influenciam na tolerância e no desencadeamento de reações adversas e preconizam que sua utilização seja feita de forma racional (Juchem et al. 2004, Widmark 2007, Carraro-Eduardo et al. 2008).

Os mecanismos de ação dos MCI sobre os rins são complexos e embora não estejam totalmente elucidados, destacam-se efeitos hemodinâmicos que promovem vasoconstrição intrarrenal prolongada com consequente redução da perfusão renal, hipóxia e isquemia medular, que se somam à injúria direta sobre o epitélio tubular, propiciando a redução da taxa de filtração glomerular (TFG) (Katzberg 2005, Thomsen et al. 2014a).

Em rins de cães adultos saudáveis, o potencial nocivo dessas substâncias foi constatado após duas doses, via intravenosa, de contraste iodado em exames de TC, pela diminuição de $17 \%$ na TFG, avaliado pela cintilografia (Kirberger et al. 2012). No homem, desidratação, senilidade, insuficiência cardíaca congestiva (ICC) e disfunção renal preexistente são consideradas fatores de risco de maior relevância, que potencializam os efeitos renais dos MCI, predispondo à reação adversa renal tardia, também denominada nefropatia induzida por contraste (NIC) (Morcos 1998, Murphy et al. 2000, Thomsen 2003, Toprak 2007, Wong \& Irwin 2007, Bartorelli \& Marenzi 2008, McCullough 2008, Pucelikova et al. 2008, Santos et al. 2011, Rudnick et al. 2014).

A NIC é definida como o declínio agudo da função renal e reconhecida pela elevação de $25 \%$ ou $0,5 \mathrm{mg} / \mathrm{dL}$ na 
creatinina basal em 24-48 horas, após a administração intravascular do agente, sem outras causas concomitantes (Morcos 1998, Murphy et al. 2000, Thomsen 2003, Katholi 2006, Bartorelli \& Marenzi 2008, Carraro-Eduardo et al. 2008, Kramer et al. 2008, McCullough 2008, Pucelikova et al. 2008, Silva et al. 2010). Como grande parte dos casos de NIC não é imediatamente evidente, devido ao curso assintomático (Bartorelli \& Marenzi 2008), a prevenção constitui a melhor forma de reduzir sua ocorrência (Thomsen 2006, Pucelikova et al. 2008).

No homem, as principais medidas preventivas consideram a manutenção do bom estado de hidratação, escolha de MCI com características específicas, suspensão da administração de fármacos nefrotóxicos pelo menos 24 horas antes da aplicação do meio de contraste e evitar a realização de múltiplos estudos contrastados em menos de 72 horas (Thomsen 2006, Pucelikova et al. 2008). Em relação à escolha do MCI como medida preventiva ao desenvolvimento da NIC, é consenso na prática médica de que meios iônicos de alta osmolaridade são mais nefrotóxicos do que não iônicos de baixa osmolaridade e isosmolares (Rudnick et al. 1995, Katzberg 1997, Morcos 1998). Entretanto, estudos têm sido realizados sobre a osmolaridade dos meios não iônicos a ser utilizada em pacientes humanos de risco com disfunção renal preexistente (Aspelin et al. 2003, Jo et al. 2006, Bartorelli \& Marenzi 2008, Thomsen et al. 2008, Reddan et al. 2009). Embora pesquisas clínicas sugiram que os agentes isosmolares apresentem nefrotoxicidade igual ou inferior aos de baixa osmolaridade, são necessárias mais investigações a respeito do assunto para que se possa chegar a um denominador comum (Sandler 2003, Reddan et al. 2009).

Em pequenos animais, aconselha-se somente não administrar contraste iodado, via intravenosa, em pacientes desidratados, hipotensos ou em anuria (Seiler 2013). Visando averiguar medidas preventivas para contrapor o desenvolvimento da NIC em cães, é fundamental compreender como os rins de animais desta espécie reagem aos MCI na prática ambulatorial. Particular atenção tem sido direcionada aos efeitos hemodinâmicos dos MCI, pois a hipóxia medular parece desempenhar um papel central no desenvolvimento da NIC (Heyman et al. 2005). Pesquisadores sugerem que a avaliação da dinâmica vascular renal por meio da técnica Doppler (Choi et al. 2001, Hetzel et al. 2001, Shakourirad et al. 2009, Rodriguez et al. 2013, Martín et al. 2014) e a avaliação da integridade do epitélio tubular por meio de análises laboratoriais como o exame de urina (Ihle \& Kostolich 1991, Ultramari et al. 2006, Kramer et al. 2008, Kirberger et al. 2012), a atividade enzimática da gama-glutamil transferase (GGT) urinária (Duan et al. 1999) e as determinações das razões GGT:creatinina (GGT:C) e proteína:creatinina (RPC) urinárias (Kirberger et al. 2012) contribuem para o entendimento dos efeitos renais relacionados à infusão intravenosa dos MCI.

Na literatura médico-veterinária não foram encontrados, até o momento, estudos que tenham caracterizado os efeitos renais da administração intravenosa de MCI não iônicos de osmolaridades distintas e nem sugerido qual desses meios pode constituir opção para prevenir a ocor- rência da NIC em pacientes ambulatoriais de risco da espécie canina.

Portanto, o objetivo deste estudo foi avaliar de modo comparativo, os aspectos ultrassonográficos (morfométricos, morfológicos, hemodinâmicos e perfusionais) e laboratoriais (função e integridade) de rins de cães que receberam contrastes iodados não iônicos de baixa osmolaridade e isosmolar, por via intravenosa em exames de TC, a fim de estimar indiretamente o potencial nefrotóxico de cada MCI. Espera-se que a escolha de um, em detrimento do outro, contribua como medida preventiva ao desenvolvimento da NIC.

Tem-se primeiramente como hipótese que o meio não iônico isosmolar é menos nocivo e, dessa forma, constitui opção favorável em pacientes de risco da espécie canina. Em segundo lugar, as técnicas Doppler colorido, de amplitude (power Doppler) e pulsado são capazes de monitorar a dinâmica vascular intrarrenal e advertir para o potencial nocivo de cada substância estudada, por meio da graduação da perfusão e a aferição dos índices hemodinâmicos intrarrenais.

\section{MATERIAL E MÉTODOS}

Animais e delineamento experimental. Esta pesquisa foi aprovada pela Comissão de Ética no Uso de Animais (CEUA) da Faculdade de Medicina Veterinária e Zootecnia (FMVZ), Universidade de São Paulo (USP) (Protocolo 2901/2013). Todos os responsáveis tomaram ciência dos procedimentos e concordaram por escrito com a inclusão de seus animais no estudo.

Foram avaliados prospectivamente 18 cães adultos, entre 8 e 17 anos de idade, machos e fêmeas, oito sem definição racial (SDR), dez com raça definida (beagle, chow chow, cocker spaniel inglês, labrador retriever e poodle) e pesos entre 4,5 e $50 \mathrm{~kg}$. $0 \mathrm{~s}$ cães foram encaminhados ao Serviço de Diagnóstico por Imagem do Departamento de Cirurgia junto ao Hospital Veterinário da FMVZ USP para estadiamento e avaliação da viabilidade cirúrgica de neoformações originadas em qualquer região, por meio do exame de TC (equipamento de TC helicoidal, com uma única fileira de detectores, modelo XPRESS/G6, Toshiba ${ }^{\circledR}$ ) com contraste. Foram incluídos animais que apresentassem um ou ambos os fatores de risco para o desenvolvimento de NIC: idade igual ou superior a dez anos e insuficiência cardíaca assintomática (categorias Ia e Ib, segundo a International Small Animal Cardiac Health Council, 1999). 0 limite máximo de concentração sérica de creatinina considerado para a inclusão dos animais foi 1,4mg/dL (Lees 2004). Foram excluídos animais que apresentassem caquexia e desidratação, por se tratarem de condições que notoriamente tornam os cães vulneráveis ao desenvolvimento da NIC. Verificou-se o adequado estado de hidratação dos cães pelo índice de turgor cutâneo, brilho ou umidade de mucosas aparentes, hematócrito, proteína plasmática total e densidade urinária, previamente à anestesia e ao exame tomográfico.

Constituíram-se dois grupos de acordo com o MCI utilizado: primeiramente, o grupo GIH, no qual onze animais receberam agente não iônico de baixa osmolaridade (iohexol) e posteriormente, o grupo GID, no qual sete cães receberam agente não iônico isosmolar (iodixanol). A administração foi realizada manualmente, em bolus, via intravenosa (veia cefálica ou safena), na dose de 600mgl/kg (Pollard \& Puchalski 2012), não ultrapassando o volume de $90 \mathrm{ml}$ (Owens \& Biery 1998). O iohexol apresentou concentração de $300 \mathrm{mgI} / \mathrm{ml}$ (Omnipaque $300^{\circledR}$, GE Healthcare) e o iodixanol de $270 \mathrm{mgI} / \mathrm{ml}$ (Visipaque270 ${ }^{\circledR}$, GE Healthcare). Ambos 
foram administrados à temperatura ambiente (entre 20 e $23^{\circ} \mathrm{C}$ ) apresentando viscosidades semelhantes $(11,6 \mathrm{cps}$ e $12,2 \mathrm{cps}$, respectivamente). Embora tenham constituído diferentes grupos de análise (GIH e GID), cada animal deste estudo foi considerado seu próprio controle.

Os animais foram submetidos ao exame físico (tais como avaliação de mucosas, estado de hidratação e palpação abdominal para avaliação da presença de sensibilidade na região lombar-renal), avaliação renal por meio da ultrassonografia modo B, Doppler colorido, de amplitude e pulsado, aferições das pressões arterial sistólica (PAS), diastólica (PAD) e média (PAM) e da frequência cardíaca (FC) e coleta de material biológico (sangue venoso e urina) para análise do perfil sérico bioquímico renal, e ocorridas em quatro momentos distintos: antes da infusão intravenosa do MCI (momento T0) e após 1h30min (momento T1), 24 horas (momento T2) e 48 horas (momento T3).

Os exames ultrassonográficos, a aferição dos sinais vitais e as coletas de material biológico foram realizados antes da sedação e anestesia geral para a realização da TC e após a completa recuperação anestésica, para assim evitar os efeitos dos fármacos sobre a hemodinâmica e perfusão renais. 0 protocolo de sedação não foi padronizado, entretanto, utilizou-se propofol $(5 \mathrm{ml} / \mathrm{kg} /$ IV) para a indução, isofluorano para a manutenção anestésica e infusão de solução Ringer com lactato de sódio (5ml/kg/hora em média) em todos os animais. Nenhum paciente desenvolveu episódio hipotensivo (PAS $\leq 80 \mathrm{mmHg}$; PAM $\leq 60 \mathrm{mmHg}$ ) que necessitasse de intervenção terapêutica medicamentosa, como também que pudesse interferir de modo irreversível na função renal (Love \& Harvey 2006).

Exame ultrassonográfico. Avaliaram-se os efeitos da administração dos MCI sobre a morfometria (comprimento e volume), morfologia (contornos, definição corticomedular e arquitetura), ecogenicidade cortical, perfusão renal e resistência vascular intrarrenal, em cada momento, pela ultrassonografia modo B, Doppler colorido, de amplitude e pulsado. Realizou-se tricotomia abdominal dos flancos direito e esquerdo, contenção manual, a fim de manter os pacientes em decúbitos dorsal e lateral, e aplicação de gel acústico específico (Ultra-Gel ULTRA ${ }^{\circledR}$, MultiGel). Utilizou-se aparelho de ultrassonografia dinâmico (MyLab ${ }^{\mathrm{TM}} 40 \mathrm{VET}$, Esaote Healthcare do Brasil), com os recursos de Doppler colorido, de amplitude e pulsado e três transdutores eletrônicos multifrequencias de banda larga (microconvexo com frequência de 5-8 $\mathrm{MHz}$, convexo de 2.5-6.6 MHz e linear de 3-11 MHz), para obtenção das medidas lineares de comprimento, altura e largura renais. Cada uma dessas medidas foi aferida três vezes e calculada a média aritmética simples. Em seguida, estimou-se o volume renal, por meio da fórmula para o volume de um elipsoide (Barr 1990). Assim, realizou-se a análise morfométrica renal, por meio dos valores de comprimento e volume. Durante a varredura, de acordo com classificação elaborada por Martín et al. (2015), avaliaram-se os rins, quanto à morfologia e quanto à ecogenicidade cortical renal, em comparação com o parênquima esplênico à esquerda e o parênquima hepático à direita:

escore morfológico 1 (morfologia preservada): ausência de alterações nos contornos, definição da junção corticomedular e arquitetura,

escore morfológico 2 (morfologia parcialmente preservada): alteração de contornos isolada ou associada a alteração de definição da junção corticomedular com arquitetura preservada,

escore morfológico 3 (morfologia não preservada): alteração da relação corticomedular isolada ou associada a dilatação de pelve, independentemente da classificação dos contornos, ecogenicidade cortical 1: preservada, ecogenicidade cortical 2: aumentada, ecogenicidade cortical 3: reduzida,

ecogenicidade cortical 4: mista, caso fossem observadas lesões focais que sugerissem cistos, infartos, pontos de mineralização ou fibrose,

ecogenicidade cortical 5: acentuadamente aumentada ou reduzida, caso fossem observadas mudanças bruscas de ecogenicidade em relação ao momento anterior.

A avaliação semiquantitativa da perfusão renal foi graduada de acordo com o preenchimento das artérias e veias renais interlobares, arqueadas e interlobulares em todo o parênquima por meio dos mapeamentos de fluxo pelo Doppler colorido e de amplitude, conforme proposto por Barozzi et al. (2007) e validado por Martín et al. (2015):

grau 0: vasos renais não identificáveis,

grau 1: poucos vasos identificáveis na proximidade do hilo renal, grau 2: vasos hilares e interlobares identificáveis na maior parte do parênquima,

grau 3: todos os vasos renais identificáveis do hilo até as artérias arqueadas/interlobulares em todo o parênquima renal.

A aferição dos índices de resistividade (IR) e de pulsatilidade (IP) foi realizada apenas a partir da análise dopplervelocimétrica das artérias interlobares do rim esquerdo, considerada suficiente para monitorar a resposta renal à infusão intravenosa de $\mathrm{MCI}$, segundo técnica validada por Martín et al. (2015). No entanto, para que somente os dados relacionados ao rim esquerdo fossem representativos dos efeitos da administração dos MCI, foi necessário que o operador constatasse na abordagem inicial (T0), que comprimento, volume, morfologia, ecogenicidade cortical e grau de perfusão dos rins direito e esquerdo fossem semelhantes. A simetria entre os rins foi verificada quando se encontrou diferença inferior a $0,59 \mathrm{~cm}$ entre os comprimentos dos rins direito e esquerdo, uma vez que essa foi a maior diferença individual entre os comprimentos renais contralaterais, encontrada num cão de porte grande (labrador retriever), na amostra onde a técnica foi validada (Martín et al. 2015).

Após o reconhecimento de similaridade entre os referidos aspectos sonográficos dos rins direito e esquerdo, realizou-se avaliação quantitativa e indireta da resistência vascular intrarrenal, por meio do IR e IP das artérias interlobares nas regiões cranial (cr), média (md) e caudal (cd) do rim esquerdo. Localizou-se a porção mais distal de cada artéria interlobar pelo mapeamento colorido, acionou-se o Doppler pulsado e posicionou-se o volume de amostra (2-4mm) sobre o vaso. Analisaram-se as artérias intrarrenais com frequências variando entre 2.5 e $6.6 \mathrm{MHz}$, filtro de parede baixo e ganho no nível máximo anterior à formação de ruídos ao fundo do espectro. Ajustou-se a pulse repetition frequency (PRF) e se selecionou a menor escala de velocidades que exibisse o traçado espectral sem aliasing. Avaliaram-se os traçados que apresentassem, de preferência, pelo menos três ondas espectrais de formato semelhante e consecutivas, sendo obtidas: velocidade de pico sistólico (VPS), velocidade diastólica final (VDF), velocidade média $(\mathrm{Vm})$, e consequentemente, os valores de IR e IP. A aquisição desses dados foi realizada imediatamente após cada exame, com auxílio do software Mylab Desk, marca Esaote ${ }^{\circledR}$. 0 traçado para determinar a Vm, e posteriormente, calcular o IP, foi desenhado à mão livre com a ajuda do mouse. Os IR obtidos em cada uma das três ondas espectrais de um traçado foram submetidos à média aritmética simples, resultando no índice de resistividade de uma determinada porção do parênquima (IRcr, IRmd ou IRcd). Considerou-se como IR intrarrenal a média aritmética simples das porções onde foi possível obter o IR regional. Quando 
foi possível aferir apenas o IR de uma região, esse foi considerado o IR intrarrenal. 0 mesmo foi feito para se obter o valor do IP.

Embora a obtenção dos dados ultrassonográficos, após cada análise, tenha sido cega em relação aos resultados das análises laboratoriais, o operador tinha prévio conhecimento de qual MCI havia sido administrado ao paciente. Para que não houvesse influência dessa informação sobre a análise da hemodinâmica renal, bem como para testar a consistência dos valores dos índices (IR e IP) aferidos inicialmente, foi realizada análise intra-observador, isto é, os traçados espectrais foram armazenados em pen drive e submetidos a uma segunda análise com novas aferições dos IR e IP, em software específico, pelo mesmo operador, porém sem conhecimento de qual MCI havia sido aplicado.

Pressão arterial sanguínea e frequência cardíaca (hemodinâmica sistêmica). A PAS, PAD, PAM e FC foram avaliadas ao longo do período experimental para averiguar a possibilidade de influência direta destes parâmetros hemodinâmicos sistêmicos sobre a dinâmica vascular renal (Platt, 1992). Aferiram-se a PAS, PAD, PAM e FC pelo método indireto oscilométrico com aparelho analógico ou digital portátil (PetMAP $\left.{ }^{\mathrm{TM}}\right)$, após o exame ultrassonográfico, permitindo adaptação com o ambiente. Os animais foram contidos em decúbito lateral esquerdo, com o manguito no membro torácico, proximal ao carpo (artéria mediana). Realizaram-se pelo menos quatro mensurações, descartou-se a primeira e se calculou a média aritmética simples dos demais valores (Brown et al. 2007).

Avaliações laboratoriais. A análise laboratorial dos efeitos da administração dos MCI sobre a integridade e função renais foi realizada em cada momento. Verificou-se a integridade do epitélio tubular por meio do estabelecimento da razão GGT:C urinária, glicemia em conjunto com a glicose urinária e análise do sedimento urinário (hemácias, leucócitos, cilindros, células de epitélio transicional e renal, cristais, bactérias e filamentos de muco). Avaliou-se a função das células tubulares relacionada à capacidade de reabsorção adequada de proteína, ao longo do tempo, por meio de mensuração semiquantitativa de proteinúria (método de fita reagente) e quantitativa pela RPC. Já a função tubular em relação à habilidade para concentrar a urina foi avaliada por meio da densidade urinária. Por fim, avaliou-se indiretamente a TFG pelo marcador referente à concentração sérica de creatinina. 0 estado de hidratação dos cães, no decorrer do período experimental, foi verificado pelo índice de turgor cutâneo, brilho ou umidade de mucosas aparentes, hematócrito, proteína plasmática total e densidade urinária.

Foram coletadas amostras de $3 \mathrm{ml}$ de sangue por venopunção jugular, acondicionadas apropriadamente em tubos contendo o anticoagulante ácido etilenodiamino tetracético (EDTA) para determinação de hematócrito (Centrífuga para microhematócrito MH, CELM) e proteínas totais (Portable refractometer Co., Ltd Pequim); e tubos contendo gel coagulante para dosagem sérica de creatinina (kit comercial Creatinina K, Labtest e analisador bioquímico LABMAX240, Labtest). Os níveis glicêmicos foram determinados em até 30 segundos após a coleta, utilizando-se glicosímetro portátil (Accu-Chek Performa ${ }^{\circledR}$, Roche). As amostras de urina foram coletadas por cistocentese e processadas em até quatro horas. A densidade urinária foi determinada por refratometria (Refratômetro UGI Atago), a proteína e a glicose por meio de tiras reagentes (Combur ${ }^{10} \mathrm{Test}^{\circledR}$, Roche) e a análise do sedimento, após centrifugação da urina (Centrifuge 5702, Eppendorf), em microscopia óptica e aumento de 400x (CX21, Olympus). A RPC e a razão GGT:C foram calculadas a partir das concentrações urinárias de creatinina e proteína e da atividade da GGT urinária [kits comerciais específicos: Creatinine K, Labtest; Sensiprot, Labtest; Gamma-glutamiltransferase ( $\gamma$-GT), BioSystems e analisador bioquímico LABMAX240, Labtest]. Valores da RPC somente foram considerados quando o sedimento urinário se encontrava inativo, ou seja, na ausência de elementos tais como células, cilindrúria ou bacteriúria, na abordagem inicial (momento T0) (Grauer 2007).

Manifestações clínicas. Após as avaliações nos momentos T1 e T2, os cães foram dispensados para retorno ao domicílio e os responsáveis orientados quanto à manutenção da dieta habitual, oferecimento de água ad libitum e reconhecimento de manifestações clínicas, como êmese e reduções notórias de volume urinário. Após as análises em T3 e até uma semana, os responsáveis foram orientados a comunicar a ocorrência das manifestações clínicas supracitadas, por meio de contato telefônico.

Análise estatística. As manifestações clínicas e os dados do exame físico foram avaliados individualmente, em cada momento.

As classificações de morfologia renal, ecogenicidade cortical e os graus de perfusão renal pelos Doppler colorido e de amplitude mantiveram-se praticamente inalterados ao longo do tempo, não sendo necessária aplicação de testes de hipótese estatística.

Para as determinações semiquantitativas de proteína urinária, ausência ou presença de glicose urinária e parâmetros avaliados no sedimento urinário realizaram-se análises descritivas. As variáveis ultrassonográficas morfométricas (comprimento e volume) e hemodinâmicas (IR e IP) do rim esquerdo e as variáveis laboratoriais (razão GGT:C, RPC, densidade urinárias e creatinina sérica) de cada grupo, foram apresentadas em quadros de média, desvio padrão e gráficos box plot representando medianas, quartis, mínimos e máximos, em cada momento avaliado (Bussab \& Morettin 2010).

Para avaliar a evolução das variáveis contínuas ao longo do tempo, comparando os grupos (GIH e GID), ajustaram-se modelos não-paramétricos para medidas repetidas (quatro repetições no tempo) interagindo com a variável grupo (Quadro 1). A análise de variância (ANOVA) verificou a existência de interação grupo:tempo, efeito de tempo ou grupo. 0 nível de significância estabelecido foi de $5 \%$ (Brunner et al. 2002).

Para cada variável que apresentasse interação significante $(\mathrm{p}<0,05)$, realizaram-se comparações múltiplas entre os grupos para cada momento e entre os momentos, dois a dois, para cada grupo (Quadro 2). Para cada variável que não apresentasse interação significante $(p>0,05)$, mas o efeito de tempo fosse significante, realizaram-se comparações múltiplas entre os momentos dois a dois, conjuntamente para os dois grupos (Quadro 3). Se o efeito do grupo fosse significante, não foram realizadas comparações múltiplas, uma vez que existem somente dois grupos, assim concluiu-se o teste diretamente pela ANOVA (Quadro 1).

Foram realizados testes de correlação entre as variáveis de hemodinâmica renal (IR e IP) e os parâmetros laboratoriais (razão GGT:C, RPC e densidade urinárias e creatinina sérica), entre o IR e o IP renais e entre as variáveis de hemodinâmica renal (IR e IP) e hemodinâmica sistêmica (PAS, PAM, PAD e FC), apresentando o coeficiente de correlação de Spearman e testando o mesmo a partir da hipótese nula de que não há correlação ( $\mathrm{r}=0$ ) (Lehmann \& D'abrera 2006).

Para avaliar a consistência das aferições do IR e do IP renais realizadas inicialmente com conhecimento de qual MCI havia sido aplicado em determinado paciente, e posteriormente às cegas, foram construídos gráficos de Bland-Altman e calculados coeficientes de correlação de concordância de Lin, no qual o valor do coeficiente de concordância $\left(r_{c}\right)$ pode variar de 0 a 1 , representando 1 a concordância máxima e 0 somente se a correlação entre as variáveis for nula (Bland \& Altman 1986, Lin 1989).

A análise estatística foi realizada por meio do software estatístico R 3.1.0 (R CORE TEAM, 2014), com auxílio do pacote ggplot2 (Wickham 2009) para os gráficos. 
Quadro 1. Valores da média e de desvio padrão das variáveis ultrassonográficas e laboratoriais, segundo o grupo (GIH = contraste iohexol; GID= contraste iodixanol) e o tempo (quatro momentos de avaliação), e avaliação estatística (ANOVA)

\begin{tabular}{|c|c|c|c|c|c|c|c|c|c|c|c|c|}
\hline \multirow[t]{2}{*}{ Variável } & \multirow{2}{*}{$\begin{array}{c}\text { Momentos } \\
\text { Grupos }\end{array}$} & \multicolumn{2}{|c|}{ T0 } & \multicolumn{2}{|c|}{$\mathrm{T} 1$} & \multicolumn{2}{|c|}{$\mathrm{T} 2$} & \multicolumn{2}{|c|}{ T3 } & \multicolumn{3}{|c|}{ valor $\mathrm{p}$} \\
\hline & & Média & DP & Média & DP & Média & DP & Média & DP & interação & grupo & tempo \\
\hline \multirow[t]{2}{*}{ Comprimento $(\mathrm{cm})$} & $\mathrm{GIH}$ & 5,47 & 1,30 & 5,68 & 1,30 & 5,60 & 1,26 & 5,52 & 1,18 & 0,369 & 0,107 & 0,001 \\
\hline & GID & 6,42 & 1,05 & 6,52 & 0,97 & 6,43 & 1,01 & 6,45 & 1,08 & & & \\
\hline \multirow[t]{2}{*}{ Volume $\left(\mathrm{cm}^{3}\right)$} & GIH & 30,89 & 17,15 & 34,01 & 21,46 & 31,92 & 18,83 & 30,10 & 15,83 & 0,054 & 0,050 & 0,031 \\
\hline & GID & 45,58 & 18,38 & 45,61 & 18,10 & 45,88 & 18,48 & 46,09 & 18,28 & & & \\
\hline \multirow[t]{2}{*}{ IR } & GIH & 0,64 & 0,06 & 0,68 & 0,08 & 0,66 & 0,07 & 0,64 & 0,05 & 0,026 & 0,899 & 0,074 \\
\hline & GID & 0,65 & 0,04 & 0,67 & 0,04 & 0,64 & 0,03 & 0,66 & 0,03 & & & \\
\hline \multirow[t]{2}{*}{ IP } & GIH & 1,20 & 0,24 & 1,45 & 0,45 & 1,31 & 0,27 & 1,22 & 0,20 & 0,032 & 0,888 & 0,071 \\
\hline & GID & 1,23 & 0,22 & 1,34 & 0,19 & 1,18 & 0,15 & 1,24 & 0,14 & & & \\
\hline \multirow[t]{2}{*}{ GGT:C } & $\mathrm{GIH}$ & 0,212 & 0,108 & 0,572 & 0,496 & 0,296 & 0,104 & 0,251 & 0,161 & 0,009 & 0,115 & 0,001 \\
\hline & GID & 0,368 & 0,148 & 0,378 & 0,150 & 0,471 & 0,314 & 0,362 & 0,136 & & & \\
\hline \multirow[t]{2}{*}{ RPC } & GIH & 0,646 & 1,321 & 0,607 & 1,224 & 0,515 & 0,909 & 0,762 & 1,736 & 0,275 & 0,540 & 0,839 \\
\hline & GID & 0,407 & 0,308 & 0,442 & 0,288 & 0,377 & 0,231 & 0,398 & 0,238 & & & \\
\hline \multirow[t]{2}{*}{ Densidade urinária } & GIH & 1,024 & 0,010 & 1,042 & 0,016 & 1,019 & 0,010 & 1,020 & 0,012 & 0,623 & 0,011 & $<0,001$ \\
\hline & GID & 1,014 & 0,006 & 1,025 & 0,005 & 1,012 & 0,007 & 1,013 & 0,008 & & & \\
\hline \multirow{2}{*}{$\begin{array}{l}\text { Creatinina sérica } \\
(\mathrm{mg} / \mathrm{dL})\end{array}$} & $\mathrm{GIH}$ & 0,91 & 0,28 & 0,89 & 0,28 & 1,00 & 0,37 & 0,92 & 0,27 & 0,297 & 0,752 & 0,171 \\
\hline & GID & 0,87 & 0,28 & 0,84 & 0,25 & 0,86 & 0,26 & 0,89 & 0,23 & & & \\
\hline
\end{tabular}

IR = índice de resistividade, IP = índice de pulsatilidade, GGT, C = razão GGT:C, RPC = razão proteína:creatinina.

Quadro 2. Valores de p das comparações múltiplas entre os grupos para cada momento e entre os momentos para cada grupo, das variáveis em que foi considerado efeito de interação (volume renala , IR e IP intrarrenais e razão GGT:C urinária) nas avaliações da ANOVA

\begin{tabular}{cccccc}
\hline Grupos & Momentos & Volume $\left(\mathrm{cm}^{3}\right)^{\mathrm{a}}$ & IR & IP & GGT:C \\
\hline \multirow{2}{*}{ GIH vs GID } & T0 & 0,052 & 0,733 & 0,950 & 0,017 \\
& T1 & 0,094 & 0,828 & 0,978 & 0,632 \\
& T2 & 0,055 & 0,347 & 0,307 & 0,171 \\
\multirow{6}{*}{ GIH } & T3 & 0,026 & 0,416 & 0,553 & 0,050 \\
& T0 vs T1 & 0,011 & 0,009 & 0,086 & $<0,001$ \\
& T0 vs T2 & 0,863 & 0,012 & 0,098 & 0,005 \\
& T0 vs T3 & 0,252 & 0,947 & 0,762 & 0,609 \\
& T1 vs T2 & 0,165 & 0,617 & 0,234 & 0,104 \\
& T1 vs T3 & 0,009 & 0,042 & 0,019 & 0,008 \\
GID & T2 vs T3 & 0,257 & 0,010 & 0,058 & 0,096 \\
& T0 vs T1 & 0,231 & 0,141 & 0,116 & 0,859 \\
& T0 vs T2 & 0,121 & 0,691 & 0,232 & 0,414 \\
& T0 vs T3 & 0,042 & 0,364 & 0,578 & 0,985 \\
& T1 vs T2 & 0,825 & 0,020 & 0,021 & 0,575 \\
& T1 vs T3 & 0,462 & 0,277 & 0,244 & 0,919 \\
& T2 vs T3 & 0,442 & 0,150 & 0,191 & 0,248 \\
\hline
\end{tabular}

Vs = versus, IR = índice de resistividade, IP = índice de pulsatilidade, GGT, $\mathrm{C}=$ razão GGT:C. ${ }^{a}$ Considerado efeito de interação, porém sem efeito significativo de interação ao nível estabelecido de 5\%.

\section{RESULTADOS}

Nenhuma manifestação clínica foi observada ou relatada, durante o período experimental. As mucosas apresentaram-se normocoradas, não se constatou sensibilidade dolorosa renal e os cães permaneceram normovolêmicos.

0 escore de morfologia renal e a ecogenicidade cortical mantiveram-se inalterados ao longo do tempo, nos animais dos grupos estudados. Os animais dos dois grupos apresentaram perfusão renal grau 3, no momento basal (T0), tanto pelo Doppler colorido, quanto de amplitude, exceto um cão do GIH, que apresentou grau de perfusão 2 no T0. Ao longo do tempo, os graus de perfusão, avaliados por meio do Doppler colorido e de amplitude, permaneceram inalterados em todos os animais, exceto em um cão do GIH.
Quadro 3. Valores de p das comparações múltiplas entre os momentos, conjuntamente para os dois grupos, das variáveis sem efeito significativo de interação (densidade urinária e comprimento renal) nas avaliações da ANOVA

\begin{tabular}{|c|c|c|c|c|c|c|}
\hline \multirow[t]{2}{*}{ Variável } & \multicolumn{6}{|c|}{ Momentos } \\
\hline & T0 vs T1 & T0 vs T2 & T0 vs T3 & T1 vs T2 & T1 vs T3 & $\mathrm{T} 2$ vs T3 \\
\hline $\begin{array}{l}\text { Densidade } \\
\text { urinária }\end{array}$ & $<0,001$ & 0,257 & 0,197 & $<0,001$ & 0,970 & $<0,001$ \\
\hline $\begin{array}{l}\text { Comprimento } \\
\text { (cm) }\end{array}$ & $<0,001$ & 0,095 & 0,460 & 0,102 & 0,208 & 0,010 \\
\hline
\end{tabular}

Os animais de ambos os grupos apresentaram concentrações séricas de glicose dentro da normalidade e ausência de glicosúria. Na análise semiquantitativa da proteína urinária pelas fitas reagentes foi constatada alterações em dois animais do GIH e em um do GID. Em relação ao sedimento urinário, foram encontradas nos dois grupos quantidades inexpressivas de hemácias, leucócitos e bactérias em amostras de alguns indivíduos e ausência de cilindros, células de epitélio transicional e renal ou filamentos de muco, em todos os animais.

Os resultados referentes aos parâmetros que avaliaram morfometria (comprimento e volume), hemodinâmica renal (IR e IP) e lesão e função renais (razão GGT:C, RPC e densidade urinárias e creatinina sérica), em ambos os grupos, ao longo do tempo, estão descritos nos Quadros 1 a 3.

A análise do comprimento renal não apresentou interação entre os grupos, ao longo do tempo $(\mathrm{p}=0,369)$, observando-se perfis similares. 0 efeito do tempo foi significante $(\mathrm{p}=0,001)$, no qual se constatou que o comprimento renal de cada grupo teve comportamento semelhante, ou seja, a existência das mesmas variações entre os momentos: aumento de T0 para T1, retornando aos valores basais em $\mathrm{T} 2$ e T3.

0 efeito de grupo para a análise do volume renal foi significante $(\mathrm{p}=0,050)$, demonstrando que os grupos apresentaram diferenças numéricas estatisticamente detectáveis 
em todos os momentos. Nesse caso, a distribuição aleatória dos animais que constituíram cada um dos grupos resultou em indivíduos de maior porte no GID e, consequentemente, rins com maior volume. A análise do volume renal não detectou interação entre os grupos ao longo do tempo ( $\mathrm{p}=0,054)$ (Fig.1).

Na análise do IR observou-se existência de interação entre os grupos, ao longo do tempo $(\mathrm{p}=0,026)$, revelando perfis não similares. $0 \mathrm{GIH}$ apresentou maior oscilação nos valores de IR, com aumentos significantes em T1 e T2 em relação ao valor basal (T0) e redução de T1 até T3, enquanto no GID os valores permaneceram mais constantes ao longo do tempo, sem variações significantes em relação ao momento basal (Fig.2).

Quanto à análise do IP, detectou-se interação entre os grupos, ao longo do tempo $(\mathrm{p}=0,032)$, constatando-se perfis não similares. No GIH observou-se diferença significante de T1 para T3 e no GID de T1 para T2, contudo não foram observadas diferenças dos momentos em relação ao basal, concluindo-se que ambos os grupos apresentaram valores relativamente constantes ao longo do tempo.

No atinente a avaliação estatística da razão GGT:C urinária, constatou-se a interação entre os grupos, ao longo do tempo ( $\mathrm{p}=0,009)$, e a evolução dos perfis não foram simila-

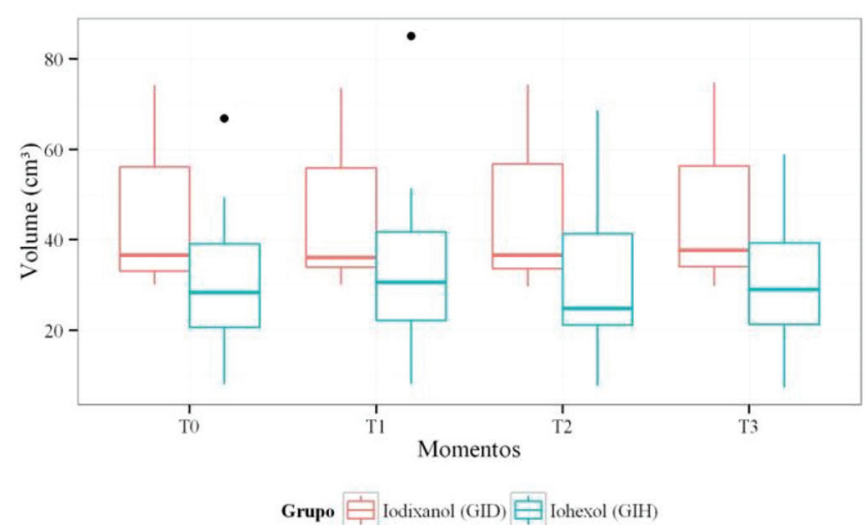

Fig.1. Boxplot para o volume renal, segundo o grupo (GIH e GID) e o momento de avaliação (T0=antes do contraste, T1=após $1 \mathrm{~h} 30 \mathrm{~min}, \mathrm{~T} 2=$ =após $24 \mathrm{~h}$ e T3=após $48 \mathrm{~h}$ )

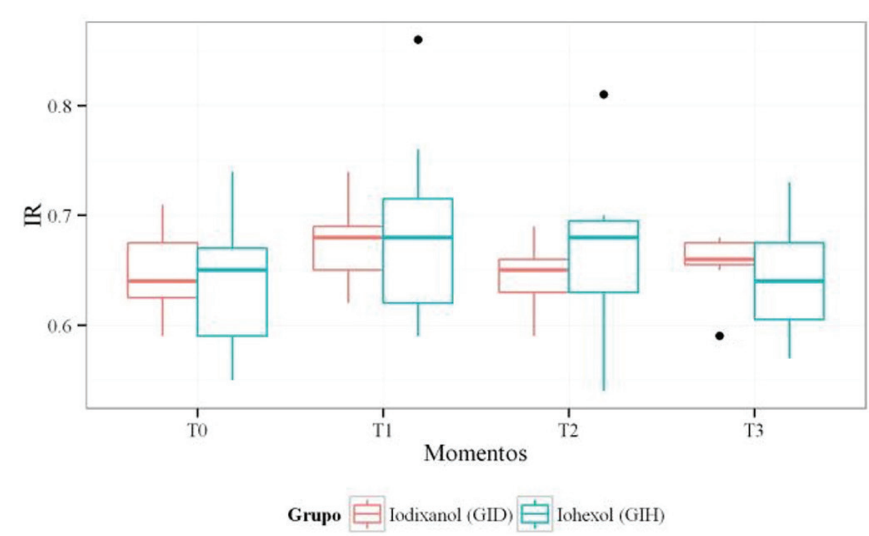

Fig.2. Boxplot para o índice de resistividade (IR), segundo o grupo (GIH e GID) e o momento de avaliação (T0=antes do contraste, T1=após 1h30min, T2=após $24 \mathrm{~h}$ e T3=após 48h)

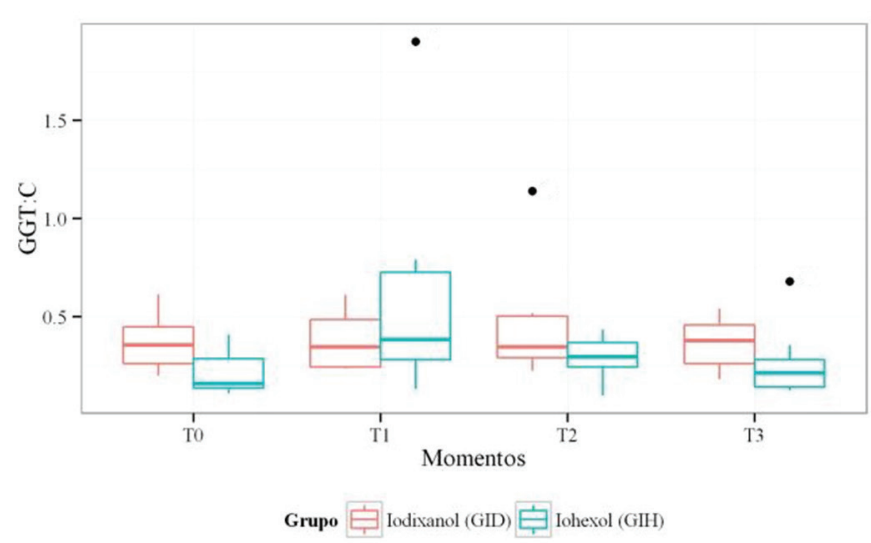

Fig.3. Boxplot para a razão gamaglutamil transferase:creatinina urinária (GGT:C), segundo o grupo (GIH e GID) e o momento de avaliação (T0=antes do contraste, T1=após $1 \mathrm{~h} 30 \mathrm{~min}$, T2=após 24h e T3=após 48h)

res. 0 GIH apresentou maior oscilação nos valores da razão GGT:C, com aumentos significantes em T1 e T2 em relação ao valor basal (T0) e redução significante de T1 para o momento final (T3), quando retorna ao valor basal. No GID não foi observada diferença estatística entre os momentos, sendo que os valores foram constantes ao longo do tempo (Fig.3).

0 efeito de grupo para a análise da densidade urinária foi significante $(\mathrm{p}=0,011)$, o que revela que ambos os grupos apresentaram diferenças numéricas estatisticamente detectáveis em todos os momentos. Justifica-se este fato, devido à diferença entre os valores de densidade urinária dos animais que constituíram aleatoriamente os grupos. Os indivíduos do GIH apresentaram em média maior densidade urinária na abordagem inicial (T0), em relação aos animais que constituíram o GID. A ausência de interação grupo:tempo $(\mathrm{p}=0,623)$ e o efeito tempo significante $(p<0,001)$ revelaram que os comportamentos dos grupos foram similares, sendo que estavam expostos as mesmas variações entre os momentos. Assim, observou-se o aumento de T0 para T1, redução de T1 para T2 e discreto aumento de T2 para T3, concluindo-se haver um pico de densidade urinária em T1. Entre o momento basal (T0) e os demais (T2 e T3) não foram observadas diferenças significantes.

As análises estatísticas da RPC urinária e da creatinina sérica não apresentaram interação e nem efeitos significantes de grupo e tempo, indicando que em relação a essas variáveis, os grupos apresentaram comportamentos similares, valores sem diferenças estatísticas entre os grupos e ausência de variações significantes ao longo do tempo.

Ainda, não foram observadas correlações significantes entre as variáveis de hemodinâmica renal (IR e IP) e os parâmetros laboratoriais (razão GGT:C, RPC e densidade urinárias e creatinina sérica), em nenhum momento (Quadro 4).

Observaram-se fortes correlações positivas entre o IR e o IP renais, considerando todos os momentos e cada um dos momentos (valor de $\mathrm{r}^{\mathrm{a}}$, quando $\mathrm{p}<0,05$ ) (Quadro 5).

Ao correlacionar as hemodinâmicas renal e sistêmica, considerando todos os momentos, observaram-se correlações negativas fracas entre o IR intrarrenal e a PAS ( $\mathrm{r}=$ $-0,316, p<0,05)$ e entre o IR intrarrenal e a PAM $(r=-0,250$, $\mathrm{p}<0,05$ ) (Quadro 5). 
Quadro 4. Correlações de Spearman, valores de "r", entre a hemodinâmica renal (IR e IP) e os parâmetros laboratoriais (razão GGT:C urinária, RPC urinária, densidade urinária e creatinina sérica) em todos os momentos e em cada momento de avaliação (T0 = antes do contraste, T1 = após $1 \mathrm{~h} 30 \mathrm{~min}, \mathrm{~T} 2$ = após $24 \mathrm{~h}$ e T3 = após 48h)

\begin{tabular}{|c|c|c|c|c|c|c|c|c|c|c|}
\hline \multirow{2}{*}{$\begin{array}{l}\text { Momentos } \\
\text { Variável }\end{array}$} & \multicolumn{2}{|c|}{ Todos os momentos } & \multicolumn{2}{|c|}{ T0 } & \multicolumn{2}{|c|}{$\mathrm{T} 1$} & \multicolumn{2}{|c|}{$\mathrm{T} 2$} & \multicolumn{2}{|c|}{ T3 } \\
\hline & IR & IP & IR & IP & IR & IP & IR & IP & IR & IP \\
\hline GGT:C & 0,033 & 0,064 & $-0,018$ & 0,022 & 0,078 & 0,219 & $-0,320$ & $-0,164$ & $-0,002$ & $-0,070$ \\
\hline RPC & 0,088 & 0,003 & 0,041 & $-0,131$ & 0,275 & 0,355 & 0,090 & 0,068 & 0,034 & $-0,022$ \\
\hline Densidade uri & 0,090 & 0,140 & 0,145 & 0,126 & 0,161 & 0,103 & $-0,089$ & $-0,194$ & $-0,239$ & $-0,130$ \\
\hline Creatinina sérica $(\mathrm{mg} / \mathrm{dL})$ & 0,045 & 0,151 & 0,064 & 0,210 & 0,064 & 0,071 & 0,082 & 0,174 & 0,144 & 0,279 \\
\hline
\end{tabular}

IR = índice de resistividade, IP = índice de pulsatilidade, GGT:C = razão GGT:C, RPC = razão proteína:creatinina. Valores de r quando p>0,05 significam que não há existência de correlação.

Considerando cada um dos momentos, observou-se somente correlação negativa moderada entre o IR intrarrenal e a PAS ( $r=-0,516, p<0,05)$, no momento T3 (Quadro 5).

As análises estatísticas, apresentadas nas Figuras 4 e 5

Quadro 5. Correlações de Spearman, valores de "r", entre o IR e o IP intrarrenais e entre a hemodinâmica intrarrenal (IR e IP) e a hemodinâmica sistêmica (PAS, PAD, PAM e FC) em todos os momentos e em cada momento de avaliação

\begin{tabular}{|c|c|c|c|c|c|c|}
\hline \multicolumn{7}{|c|}{ Todos os momentos } \\
\hline Variável & IR & IP & PAS & PAD & PAM & $\mathrm{FC}$ \\
\hline IR & 1 & $0,865^{\mathrm{a}}$ & $-0,316^{a}$ & $-0,158$ & $-0,250 a$ & $-0,127$ \\
\hline IP & $0,865^{\mathrm{a}}$ & 1 & $-0,201$ & $-0,139$ & $-0,183$ & 0,017 \\
\hline \multicolumn{7}{|c|}{ Momento T0 } \\
\hline Variável & IR & IP & PAS & PAD & PAM & FC \\
\hline IR & 1 & $0,925^{\mathrm{a}}$ & $-0,468$ & $-0,157$ & $-0,303$ & $-0,026$ \\
\hline IP & $0,925^{\mathrm{a}}$ & 1 & $-0,288$ & $-0,066$ & $-0,165$ & 0,182 \\
\hline \multicolumn{7}{|c|}{ Momento T1 } \\
\hline Variável & IR & IP & PAS & PAD & PAM & $\mathrm{FC}$ \\
\hline IR & 1 & $0,845^{\mathrm{a}}$ & $-0,233$ & $-0,121$ & $-0,193$ & 0,127 \\
\hline IP & $0,845^{\mathrm{a}}$ & 1 & $-0,152$ & $-0,102$ & $-0,139$ & 0,348 \\
\hline \multicolumn{7}{|c|}{ Momento T2 } \\
\hline Variável & IR & IP & PAS & PAD & PAM & $\mathrm{FC}$ \\
\hline IR & 1 & $0,898^{\mathrm{a}}$ & $-0,026$ & $-0,03$ & $-0,037$ & 0,052 \\
\hline IP & $0,898^{\mathrm{a}}$ & 1 & 0,033 & 0,022 & 0,025 & 0,137 \\
\hline \multicolumn{7}{|c|}{ Momento T3 } \\
\hline Variável & IR & IP & PAS & PAD & PAM & FC \\
\hline IR & 1 & $0,783^{\mathrm{a}}$ & $-0,516^{a}$ & $-0,188$ & $-0,352$ & $-0,431$ \\
\hline IP & $0,783^{\mathrm{a}}$ & 1 & $-0,228$ & $-0,236$ & $-0,264$ & $-0,361$ \\
\hline
\end{tabular}

IR = índice de resistividade, IP = índice de pulsatilidade, $\mathrm{PAS}=$ pressão arterial sistólica, $\mathrm{PAD}=$ pressão arterial diastólica, $\mathrm{PAM}=$ pressão. arterial média, $\mathrm{FC}=$ frequência cardíaca. ${ }^{a}$ Valores de $\mathrm{r}$ quando $\mathrm{p}<0,05 \mathrm{sob}$ hipótese de nulidade da correlação.

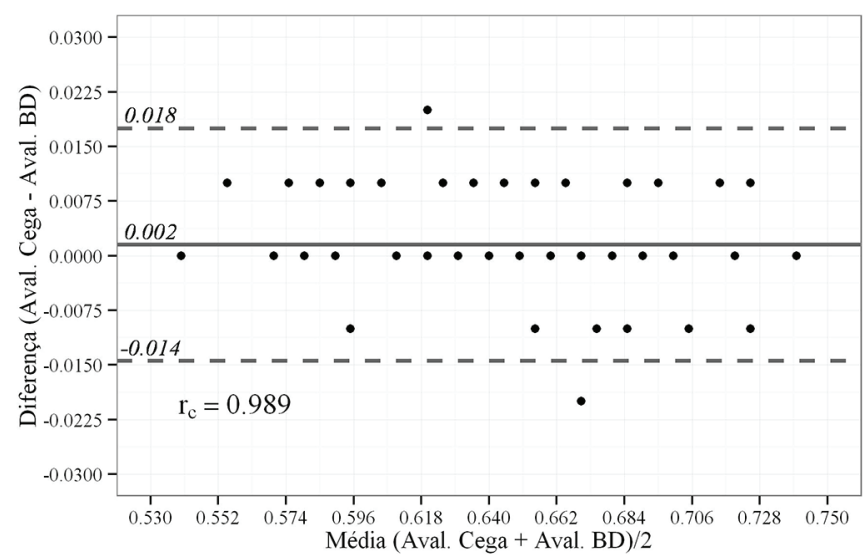

Fig.4. Gráfico de Bland-Altman para o índice de resistividade (IR), segundo a avaliação inicial com conhecimento do meio de contraste utilizado e a avaliação cega.

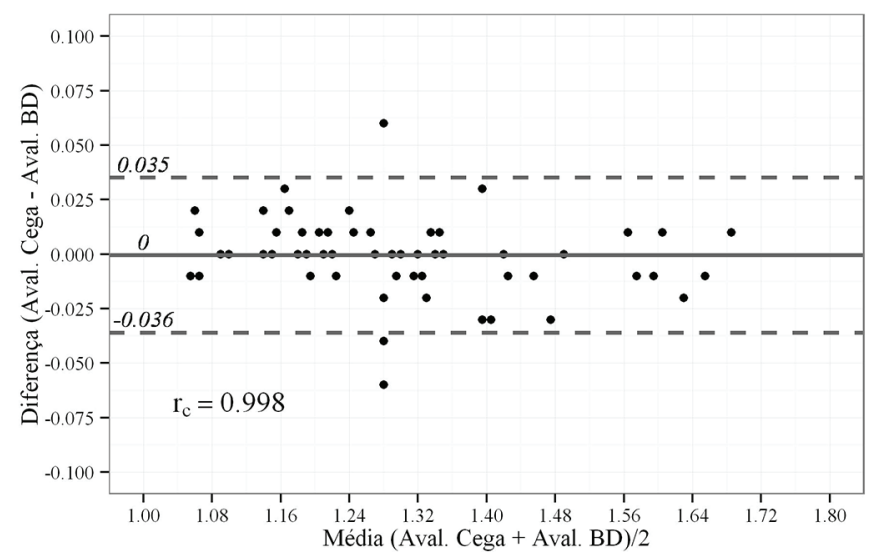

Fig.5. Gráfico de Bland-Altman para o índice de pulsatilidade (IP), segundo a avaliação inicial com conhecimento do meio de contraste utilizado e avaliação cega.

de Bland-Altman sustentam que a aferição inicial dos índices hemodinâmicos não sofreu influência do conhecimento de qual MCI havia sido aplicado, uma vez que as aferições cegas posteriores apresentaram intervalo do viés médio de $-0,014$ a 0,018 para o IR e -0,036 a 0,018 para o IP. Ademais, não há efeito de linearidade entre as diferenças, ou seja, os pontos não apresentam tendência linear (os erros positivos não ocorreram mais frequentemente para um lado e os negativos para o outro). Os coeficientes de correlação de Lin $\left(r_{c}\right)$ foram todos superiores a 0,9 , indicando consistência entre as avaliações iniciais e posteriores cegas.

A ausência de variações significantes nas aferições do IR e do IP validaram a reprodutibilidade intra-observador da obtenção do traçado manual desenhado à mão livre para as determinações das VPS, VDF e, primordialmente, da Vm.

\section{DISCUSSÃO}

A escolha dos momentos para as análises foi baseada na possibilidade de ocorrência das reações adversas devido à nefrotoxicidade pelo tempo decorrido após a administração de MCI, como também pela recuperação anestésica. Como a NIC é considerada uma reação adversa tardia que ocorre após 60 minutos ou até uma semana após a aplicação intravascular dos contrastes (Morcos \& Thomsen 2001, Stacul 2006, Thomsen 2011, Stacul \& Bellin 2014), e o tempo para plena recuperação dos efeitos anestésicos do propofol e do isofluorano considerado foi em média 60 minutos, estipulou-se que o primeiro momento para avaliar os efeitos dos contrastes sobre a hemodinâmica renal seria de 1 hora e 
30 minutos. No homem, a NIC pode ser definida pela elevação de $25 \%$ ou $0,5 \mathrm{mg} / \mathrm{dL}$ na concentração da creatinina sérica basal em 24-48 horas, após a administração do MCI, sem outras causas concomitantes (Morcos 1998, Thomsen 2003). Em cães, segundo o critério de graduação da lesão renal aguda (LRA) da International Renal Interest Society (IRIS), o grau I pode corresponder à lesão renal com ausência de azotemia e oligúria e com aumento igual ou superior a $0,3 \mathrm{mg} / \mathrm{dL}$ na creatinina sérica basal, dentro de 48 horas. Como não existe definição de NIC para a espécie canina, os demais momentos de avaliação, 24 e 48 horas, basearam-se no fato desse intervalo ser considerado comum, tanto para a definição de NIC no homem, quanto para ocorrência de LRA no cão.

Como os contrastes radiológicos aumentam a viscosidade do sangue e intensificam efeitos vasoativos e citotóxicos (Seeliger et al. 2012), os selecionados para este estudo, ao serem administrados à temperatura ambiente, apresentaram viscosidades semelhantes [11,6cps para o iohexol (baixa osmolaridade) e 12,2cps para o iodixanol (isosmolar)] sendo a influência desta propriedade praticamente a mesma, a fim de não interferir de modo relevante na comparação do potencial nefrotóxico dos MCI avaliados neste estudo.

Inicialmente sabe-se de que os efeitos hemodinâmicos renais relacionam-se ao maior gradiente osmótico promovido pelas moléculas do MCI que não sofrem reabsorção tubular, impedem a reabsorção de água e sódio nos túbulos e estimulam diurese e natriurese. A diurese, por sua vez, aumenta o fluxo de líquido e a pressão intratubulares desencadeando vasoconstrição das arteríolas aferentes, através do mecanismo de feedback tubuloglomerular e, consequentemente, vasoconstrição intrarrenal prolongada, redução da perfusão renal, hipóxia e isquemia medular (Morcos \& Thomsen 2001, Santos et al. 2009). O MCI também é responsável pela liberação de mediadores endógenos vasoativos constritores (endotelina e adenosina) e pela redução da produção intrarrenal de vasodilatadores (óxido nítrico e prostaciclina) o que contribui para a redução da perfusão renal (Morcos \& Thomsen 2001, Santos et al. 2009). Neste estudo, os efeitos relacionados à diurese e à dinâmica vascular intrarrenal promovidos pelas diferentes osmolaridades dos contrastes utilizados, puderam ser avaliados indiretamente e comparados pela ultrassonografia modo B e pela técnica Doppler.

Em um estudo de ultrassonografia modo B, observou-se que esta foi adequada para detectar o aumento transitório do comprimento e da largura de rins de cães, secundário à utilização de $\mathrm{MCI}$ de alta osmolaridade associado à furosemida, durante urografias excretoras (Konde et al. 1984). No presente estudo, o comprimento renal dos cães que receberam MCI de diferentes osmolaridades aumentou significativamente após 1 hora e 30 minutos da aplicação de ambos os MCI. Este achado foi similar ao relatado em felinos após o uso de MCI de alta osmolaridade (Walter et al. 1987). Assim, pode-se supor que contrastes de baixa osmolaridade e isosmolar proporcionaram certo incremento do comprimento renal logo após a infusão intravenosa, e que provavelmente tenha sido em decorrência da expan- são medular. Santos et al. (2009) citaram que o gradiente osmótico, promovido pelas moléculas dos MCI e também responsável por estimular a diurese, é maior nos meios de alta osmolaridade, moderado nos de baixa osmolaridade e praticamente nulo nos isosmolares. Desse modo, caso fosse diretamente relacionado à diurese osmótica, à expansão medular e ao aumento das dimensões renais, esperar-se-ia que o comprimento renal do GIH fosse significantemente maior que do GID. Entretanto, a análise desta variável pela ultrassonografia modo B não detectou diferenças entre os efeitos do meio de baixa osmolaridade e do isosmolar.

$\mathrm{Na}$ análise do volume renal, não foi possível confirmar a interação ao nível de significância estabelecido, com a quantidade de animais avaliada no estudo. No entanto, considerando a análise gráfica dos grupos (Figura 1), sugere-se que exista essa interação, pois se observou uma sinalização de que o GIH apresentou maior oscilação do volume, com aumento significante após 1 hora e 30 minutos da administração do contraste, e com diminuição significante em 48 horas, enquanto o GID, o apresentou mais constante ao longo do tempo. Considerando que o volume renal pode ser mais expressivo ao avaliar a expansão medular, por utilizar três dimensões lineares, poder-se-ia sugerir que o MCI de baixa osmolaridade promoveu maior diurese em relação ao isosmolar, como foi comprovado por Murakami et al. (1998) por meio da análise do volume urinário do paciente humano. Este fato sustenta a hipótese levantada em alguns estudos médicos de que o MCI de baixa osmolalidade seria mais nocivo em pacientes de risco para o desenvolvimento da NIC (Aspelin et al. 2003, Jo et al. 2006, Bartorelli \& Marenzi 2008), pois a maior diurese, maior fluxo e aumento da pressão intratubular intensificariam a vasoconstrição intrarrenal e resultariam em hipóxia e isquemia medular renal com consequências relevantes (Bartorelli \& Marenzi 2008).

A morfologia renal e a ecogenicidade cortical mantiveram-se inalteradas ao longo do tempo, em todos os cães dos dois grupos estudados. Assim, a infusão intravenosa de $\mathrm{MCI}$, na dose estipulada nesse experimento, não foi capaz de causar alterações sonográficas morfológicas e de ecogenicidade renais perceptíveis pelo operador, em ambos os grupos, de modo semelhante ao constatado em felinos após o uso, via intravenosa, de MCI de alta osmolaridade (Walter et al. 1987). Entretanto, esses achados não descartam a possibilidade de ocorrência de danos tubulares, visto que rins de cães adultos, histologicamente diagnosticados com diferentes graus de necrose tubular secundária à intoxicação experimental por gentamicina, não apresentaram alterações sonográficas morfológicas ou de ecogenicidade (Rivers et al. 1996a).

É indiscutível que alterações de impedância vascular podem constituir os primeiros sinais de modificação funcional dos rins, uma vez que a função renal depende dos fluxos sanguíneo e urinário e das funções glomerular e tubular (Morrow et al. 1996). Logo, o método Doppler pode auxiliar no diagnóstico precoce de doenças renais intrínsecas, evitando o agravamento de processos agudos, uma vez que os pacientes podem ser assintomáticos em estágios iniciais (Morrow et al. 1996, Melo et al. 2006), como é o caso de grande parte das ocorrências de NIC (Bartorelli \& 
Marenzi 2008). Aumentos da diurese, fluxo e pressão intratubulares, liberação de mediadores endógenos vasoativos constritores e menor produção intrarrenal de vasodilatadores pelos MCI (Morcos \& Thomsen 2001) podem reduzir o fluxo diastólico em um maior grau do que o fluxo sistólico, resultando em uma VDF mais baixa, e consequentemente aumento do IR (Morrow et al. 1996). Hetzel et al. (2001) ao examinarem pacientes humanos adultos apresentando função renal normal, que receberam MCI de baixa osmolaridade (iopamidol), via intravenosa, detectaram aumento significante do IR intrarrenal (artéria interlobar) no período de dois e 15 minutos após a administração do MCI, comprovando-se, assim, a confiabilidade da técnica para avaliar variações de resistência vascular intrarrenal. Dessa forma, o IR intrarrenal pode ser recomendado para investigar mecanismos hemodinâmicos secundários ao uso de contrastes radiológicos. No presente estudo, o GIH teve maior oscilação dos valores do IR intrarrenal, isto é, apresentou aumentos significantes após 1 hora e 30 minutos e após 24 horas e redução significante em 48 horas, enquanto que o GID apresentou valores de IR mais constantes, ou seja, sem diferenças significantes entre o momento basal e os demais. Desse modo, embora os valores médios do IR de ambos os grupos tenham se mantido dentro dos limites de normalidade, a teoria de que o contraste de baixa osmolaridade intensifica a vasoconstrição intrarrenal de modo mais pronunciado que o meio isosmolar (Aspelin et al. 2003, Jo et al. 2006, Bartorelli \& Marenzi 2008), pôde ser comprovada. Como relatado na espécie humana (Shakourirad et al. 2009), e também observado nesta pesquisa, o IR sugeriu maior vasoconstrição intrarrenal após o uso do meio de baixa osmolaridade, podendo comprometer a perfusão renal de modo mais expressivo e tornar os rins mais vulneráveis à lesões.

A avaliação in vitro da produção do óxido nítrico (potente vasodilatador intrarrenal) pelas células da musculatura lisa da artéria renal de ratos expostos a MCI de diferentes osmolaridades demonstrou que o meio isosmolar (iodixanol) foi o único que não reduziu significantemente a síntese do óxido nítrico, sugerindo ausência ou menor grau de bloqueio em uma das vias responsáveis pela vasodilatação e autorregulação intrarrenal após a utilização de contrastes radiológicos (Ribeiro et al. 2004). Portanto, acredita-se que a utilização do meio isosmolar justificaria a menor variação da vasoconstrição intrarrenal, ao longo do tempo, constatada pelos valores constantes do IR no GID.

Nesta pesquisa, aferiu-se também o IP intrarrenal. O IR e o IP intrarrenais são considerados uma expressão da resistência à passagem do fluxo sanguíneo arterial (Morrow et al. 1996, Novellas et al. 2007) e apresentam forte correlação (Schnell \& Darmon 2012). Teoricamente, o IP pode ser considerado mais sensível para diferenciar espectros de ondas anormais e detectar variações na resistência, uma vez que o denominador é a velocidade média durante um ciclo cardíaco completo (Novellas et al. 2007). 0 GIH e o GID apresentaram valores médios do IP maiores no período de 1 hora e 30 minutos após a aplicação dos contrastes, contudo não foram detectadas diferenças significantes entre os momentos basais e os demais, pois os valores eram relativamente mais constantes que os do IR, em ambos os grupos. Embora tenha sido constatada forte correlação estatística entre o IR e o IP em todos os momentos avaliados, o IP não acompanhou os aumentos da resistência vascular intrarrenal pós-contraste. Isso poderia ser justificado, pois o IP tem demonstrado estar sujeito a maiores variações de reprodutibilidade que o IR renal (Schnell \& Darmon 2012). Entretanto, neste estudo, quando os espectros Doppler obtidos durante o período experimental foram avaliados posteriormente pelo mesmo operador, constatou-se boa reprodutibilidade tanto do IP, quanto do IR, sem variações significantes na análise intra-observador. Segundo Schnell e Darmon (2012) o IP é considerado menos apropriado ao estudo dos territórios vasculares de baixa impedância, como o leito renal, o que defenderia a preferência do estudo do IR na maioria das publicações relacionadas à dinâmica vascular renal. Logo, o fato do IP não ter verificado aumentos da resistência vascular intrarrenal, como o IR demonstrou, permite supor que este último seja de fato mais apropriado para a avaliação da dinâmica vascular intrarrenal, após a utilização dos MCI.

Justifica-se a não obtenção de espectros Doppler por outro operador, para constituir a análise de reprodutibilidade inter-observador, devido à relativa demora na obtenção dos espectros de velocidade e a necessidade de pareamento das aferições dos índices hemodinâmicos em momentos distintos e pré-determinados (1 hora e 30 minutos, 24 e 48 horas após a aplicação dos MCI).

É válido mencionar que nenhum dos animais avaliados apresentou hipotensão sistêmica ou acentuada bradicardia, que pudessem interferir diretamente na dinâmica vascular intrarrenal ou na avaliação dos efeitos dos MCI pelo IR, uma vez que na espécie humana, estas condições sistêmicas podem alterar o IR na ausência de enfermidade renal intrínseca (Platt 1992). Considerando-se todos os momentos pontuados neste estudo, as correlações entre os parâmetros que avaliaram a hemodinâmica sistêmica (PAS, PAD, PAM e FC) e a hemodinâmica renal (IR e IP) foram significantes entre o IR e a PAS e o IR e a PAM, contudo, as correlações constatadas foram consideradas fracas. De modo geral, os cães do presente estudo encontravam-se mais tranquilos logo após a completa recuperação anestésica (T1) e apresentaram menores valores de PAS e PAM, e maiores valores do IR intrarrenal, sobretudo no GIH. No entanto, especificamente no momento T1, quando a presença do efeito do MCI na dinâmica vascular intrarrenal era esperada, não foram observadas correlações significantes entre os parâmetros que avaliaram a hemodinâmica sistêmica e a hemodinâmica renal, concluindo-se que pequenas variações da pressão arterial não interferiram na análise dos efeitos dos MCI na dinâmica vascular intrarrenal.

A graduação da perfusão renal utilizou os mapeamentos do fluxo do parênquima renal pelos métodos Doppler colorido e de amplitude. Teoricamente, a diferença entre essas técnicas é que na segunda há um aumento da captação de retorno dos sinais Doppler, sem levar em consideração a velocidade ou direção de fluxo de sangue (Kodaira 2002, Engelhorn et al. 2006). Atualmente, sabe-se que é possível reconhecer a direção do fluxo, no entanto, há redução da 
sensibilidade na captação do sinal. Sua vantagem consiste na possibilidade de estudos de baixo fluxo nas diversas partes do corpo, especialmente onde os sinais são fracos, seja pelo calibre ou profundidade dos vasos (Szatmári et al. 2001). Consequentemente, o Doppler de amplitude é considerado três vezes mais sensível do que o Doppler colorido (Engelhorn et al. 2006). Todavia, a avaliação da perfusão renal neste estudo resultou em achados semelhantes pelas duas técnicas, ou seja, o grau de perfusão renal foi o mesmo quando analisado pelo Doppler colorido e de amplitude, permanecendo inalterado ao longo do tempo em todos os animais, salvo em um indivíduo do GIH.

Em estudos de perfusão de rins transplantados humanos, o Doppler de amplitude apresentou boa correlação com a TFG, sendo a intensidade da perfusão da cortical renal captada pelo Doppler de amplitude, diretamente proporcional à função renal (Hoyer et al. 1999, Engelhorn et al. 2006). Embora neste estudo não tenha sido possível correlacionar a graduação da perfusão renal e a TFG avaliada indiretamente pela creatinina sérica, verificou-se redução da perfusão renal na região cortical de ambos os rins de um cão do GIH, 1h e 30 minutos após a aplicação do MCI, com aumento absoluto de $0,5 \mathrm{mg} / \mathrm{dL}$ na creatinina sérica basal, em 24 horas. A magnitude alcançada pela creatinina sérica, 24 horas após o uso do MCI, comprova não apenas a ocorrência de NIC, pela definição dessa enfermidade no homem, como também, a ocorrência de LRA não azotêmica no cão, segundo a IRIS (2013). Dessa forma, levanta-se a hipótese de que a redução da perfusão renal possa ser preditiva de NIC. Como não foi avaliada uma quantidade expressiva de animais, a correlação entre a perfusão renal e o aumento da concentração de creatinina sérica pode ter ocorrido ao acaso, sendo necessários estudos com maior número de pacientes. Embora a análise semiquantitativa da perfusão renal pareça promissora, a grande desvantagem dos mapeamentos de fluxo pelo Doppler colorido e de amplitude são os artefatos gerados pela movimentação abdominal (Engelhorn et al. 2006), o que é muito frequente na espécie canina, em decorrência da respiração ofegante, e constituiu uma das maiores dificuldades técnicas observada neste experimento.

Durante a avaliação do preenchimento dos vasos intrarrenais pelo Doppler colorido e de amplitude, observou-se dificuldade de captação de sinais nos cães de maior porte, seja por obesidade ou tensão muscular, devido à localização renal em planos mais profundos, principalmente do rim direito (Novellas et al. 2007). Todavia, os artefatos de moção e a localização mais profunda do rim direito dos animais maiores não constituíram uma trava técnica que invalidasse a utilização do mapeamento do fluxo para inferir o grau de perfusão renal nesses pacientes ao longo do tempo.

0 efeito citotóxico dos MCI diretamente no epitélio dos túbulos renais pode provocar apoptose celular, em lesões menos graves, ou necrose tubular aguda, em lesões mais graves. Ainda que tenha sido demonstrado in vitro que células de túbulo proximal cultivadas na presença de contraste apresentaram alterações histológicas, compatíveis com toxicidade (Humes et al. 1987), lesões podem ocorrer em qualquer segmento tubular e levam a descamação celular, que resulta na formação de cilindros, os quais obstruem os túbulos em diferentes graus e contribuem para redução da TFG (Thadhani et al. 1996). Neste estudo, a análise comparativa dos efeitos dos MCI sobre o epitélio tubular, pôde ser realizada por meio de exames laboratoriais de rotina.

A detecção precoce da lesão tubular em cães, associada ao dano ou necrose do epitélio tubular, pode ser verificada pela atividade enzimática da GGT urinária (Greco et al. 1985, Loor et al. 2013). A razão GGT:C urinária reflete acuradamente a excreção da GGT originada das células tubulares (Grauer et al. 1995, Rivers et al. 1996b, Loor et al. 2013). Como a razão GGT:C do GIH apresentou maior oscilação, com aumentos significantes após 1 hora e 30 minutos e 24 horas em relação ao momento basal (T0), e diminuição significante em 48 horas, quando retornou ao valor inicial (T0), este achado foi similar ao relatado no homem após o uso de MCI de alta (Duan et al. 1999) e de baixa osmolaridade (Morcos 1998). Por outro lado, no GID os valores foram constantes ao longo do tempo. Murakami et al. (1998), ao compararem o agente isosmolar ao de baixa osmolaridade, no paciente humano, observaram aumentos significantes da atividade da GGT urinária durante duas horas após a administração de ambos, contudo, de modo mais pronunciado com o segundo. Analogamente, neste estudo, os valores médios da razão GGT:C dos grupos mantiveram-se dentro dos limites de normalidade, entretanto no GIH, observaram-se valores duas a três vezes maiores em relação ao valor médio basal, após 1 hora e 30 minutos da infusão do contraste, sugerindo lesão das células tubulares dos rins (Goldstein 2011) de modo mais expressivo pelo MCI de baixa osmolaridade, quando comparado ao $\mathrm{MCI}$ isosmolar. A análise individual dos pacientes de cada grupo reforça este resultado ao constatar que seis animais do GIH $(54,5 \%)$ e somente um animal do GID (14,3\%) apresentaram aumentos da razão GGT:C. Estes aumentos foram caracterizados entre 50 e 75\% nos momentos subsequentes à administração dos contrastes ( 1 hora e 30 minutos e 24 horas) e retornaram aos valores próximos aos basais em 48 horas.

De modo semelhante ao observado no GIH deste estudo, Duan et al. (1999) observaram que a atividade da GGT urinária logo após o uso de MCI em pacientes humanos com a função renal normal, não apresentou correlação significante com a TFG monitorada indiretamente pela creatinina sérica, concluindo que a injúria do epitélio tubular é transitória. Assim, acredita-se que a membrana basal do epitélio tubular permaneceu intacta, ocorrendo estímulo para proliferação e diferenciação de células viáveis, restauração da estrutura e função. Caso contrário, se ocorresse atrofia tubular e fibrose intersticial, esta prejudicaria a regeneração do epitélio e o comprometimento da função renal (Thadhani et al. 1996).

0 aumento da atividade da GGT urinária reflete a lesão da membrana da borda em escova do túbulo proximal com perda da estrutura da microvilosidade. 0 dano dessa estrutura causa redução da reabsorção e aumento da excreção de proteínas (Vianna 2006, Loor et al. 2013). Dessa forma, na avaliação da RPC de ambos os grupos, os valores permaneceram nos mesmos patamares ao longo do tempo, sem diferenças significantes com os valores basais. Por- 
tanto, não se constatou perda de função tubular em relação à capacidade de reabsorção de proteína, pela referida razão, após a utilização dos dois tipos de contraste, mesmo sendo observados indícios de maior agressão tubular, pela razão GGT:C, logo após aplicação do MCI de baixa osmolaridade. 0 paciente humano acometido por NIC pode apresentar perda proteica mínima (Ultramari et al. 2006, Kramer et al. 2008) e transitória (Janevski \& Moe 2003, Ultramari et al. 2006). Nesta pesquisa, o fato de três animais terem apresentado a RPC discretamente acima do limite de normalidade (entre 0,5 e 1,0, segundo a IRIS), antes e após a utilização do $\mathrm{MCI}$, pode estar relacionado à presença de processos neoplásicos, o que constituía uma condição preexistente comum a todos os cães avaliados (Lees et al. 2005). Como não houve proteinúria intensa, conforme observado nos animais deste estudo, com exceção de um cão, e ainda, sem associação com alterações das outras variáveis laboratoriais de avaliação indireta da função renal, como a creatinina sérica e a densidade urinária, a importância da RPC torna-se menor (Lees 2004).

A análise individual dos cães que tiveram pequenas perdas de proteína pela urina, detectadas pelas tiras reagentes, não demonstrou relação com a administração de MCI, entretanto, o exame semiquantitativo pela química seca apresenta baixa sensibilidade e especificidade em comparação com a determinação quantitativa (Tripathy et al. 2011).

Lesões no epitélio dos túbulos renais de cães, secundárias a substâncias nefrotóxicas, também podem resultar em perda da capacidade tubular para concentrar urina e, consequentemente, isostenúria (Ihle \& Kostolich 1991, Rivers et al. 1996a, Santin et al. 2006, Trhall et al. 2007). Tanto no GIH quanto no GID, a densidade urinária não apresentou diferenças significantes entre os momentos basais e 24 e 48 horas após administração do MCI, indicando não ter ocorrido perda efetiva da habilidade tubular em concentrar a urina, após a utilização dos agentes, ainda que existissem evidências de maior agressão tubular após a aplicação do meio de baixa osmolaridade.

A avaliação da função tubular pela densidade urinária não considerou as amostras de urina coletadas, 1 hora e 30 minutos após a aplicação intravenosa dos MCI, pois quando são coletadas logo após a utilização dessas substâncias apresentam densidade urinária superior a 1,040 (Del Vale 2011). Esta elevação da densidade ocorre em razão de pelo menos $98 \%$ do contraste radiológico ter sido eliminado até 24 horas após o procedimento de imagem, quando a função renal está preservada (Thomsen \& Morcos 2000). Neste estudo, observaram-se elevações súbitas e significantes da densidade urinária, 1 hora e 30 minutos após a aplicação dos dois tipos de contrastes, atribuindo-se esse fato à presença dos mesmos na urina e à interferência no método de leitura (refratometria).

Ao analisar o sedimento urinário dos cães de ambos os grupos, a ausência de células epiteliais tubulares e cilindros granulosos grosseiros indica que não ocorreu necrose das células tubulares em extensão suficiente para promover LRA, após a utilização dos MCI. Da mesma forma, nenhum dos indivíduos do GIH e GID apresentou glicosúria renal em condição de normoglicemia.
A vasoconstrição intrarrenal, redução da perfusão renal, hipóxia e isquemia medular, aliadas à injúria do epitélio tubular, secundárias ao uso intravascular de MCI, podem culminar com reduções agudas da TFG, consequentemente serem detectadas de modo indireto pela concentração de creatinina sérica e, assim, estabelecer a NIC. Os valores médios da creatinina sérica dos grupos que receberam diferentes MCI neste experimento permaneceram constantes ao longo do tempo, sem diferenças significantes com os valores basais, não se constatando declínio expressivo da TFG avaliada indiretamente. Estudos em cães que utilizaram iohexol pela via intravenosa, em doses semelhantes ou maiores que a desta pesquisa, também não detectaram aumento significantes da concentração sérica de creatinina, em diferentes situações: após 60, 80 minutos, 48 e 72 horas, em cães saudáveis ou com disfunção renal (Choi et al. 2001) e após 72 horas, em animais saudáveis (Kirberger et al. 2012) ou ASA (American Society of Anesthesiologists) 1 e 2 (Carotenuto et al. 2013).

Considerando as variáveis sonográficas que analisaram os efeitos hemodinâmicos intrarrenais (IR e IP) dos MCI, os parâmetros laboratoriais que avaliaram função e integridade renais (razão GGT:C, RPC, densidade urinária e creatinina sérica), em todos os momentos e em cada momento distinto de avaliação, nenhuma correlação foi considerada significante. Esperar-se-ia encontrar correlação positiva entre a razão GGT:C e o IR, uma vez que ambos foram capazes de detectar precocemente alterações renais, logo após a administração do MCI de baixa osmolaridade. Todavia, a ausência de variações expressivas entre as médias de cada variável, ao longo do tempo, em relação aos desvios padrão, observada neste estudo, reduziu a chance da detecção de correlações significantes. Este fato poderia ser justificado devido ao tamanho da amostra, que constitui uma limitação neste estudo.

\section{CONCLUSÃO}

O IR permite monitorar a dinâmica vascular intrarrenal e demonstrar, assim como a razão GGT:C urinária, o maior potencial nefrotóxico do MCI de baixa osmolaridade (iohe$\mathrm{xol}$ ), na dose de $600 \mathrm{mgl} / \mathrm{kg} / \mathrm{IV}$, em cães com fatores de risco para o desenvolvimento da NIC. Dessa forma, sugere-se a utilização do iodixanol como opção favorável para cães nestas condições.

\section{REFERÊNCIAS}

Aspelin P., Aubry P., Fransson S., Strasser R., Willenbrock R. \& Berg K.J. 2003. Nephrotoxic effects in high-risk patients undergoing angiography. New Engl. J. Med. 348(6):491-499.

Barozzi L., Valentino M., Santoro A., Mancini E. \& Pavlica P. 2007. Renal ultrasonography in critically ill patients. Crit. Care Med. 35(5):S198-S205.

Barr F.J. 1990. Evaluation of ultrasound as a method of assessing renal size in the dog. J. Small Anim. Pract. 31:174-179.

Bartorelli A. \& Marenzi G. 2008. Contrast-induced nephropathy. Journal of Interventional Cardiology 21:74-85.

Bland J. \& Altman D. 1986. Statistical methods for assessing agreement between two methods of clinical measurement. Lancet 327:307-310.

Brown S., Atkins C., Bagley R., Carr A., Cowgill L., Davidson M., Egner B., Elliot J., Henik R., Labato M., Littman M., Polzin D., Ross L., Snyder P. \& Stepien R. 2007. Guidelines for the identification, evaluation, and man- 
agement of systemic hypertension in dogs and cats. J. Vet. Intern. Med. 21:542-558.

Brunner E., Domhof S. \& Langer F. 2002. Nonparametric Analysis of Longitudinal Data in Factorial Experiments. Wiley, New York.

Bussab W.O. \& Morettin P.A. 2010. Estatística Básica. 6aㅡ ed. Saraiva, São Paulo.

Carotenuto A.M., Paltrinieri B.S., Giordano A., Moretti M. \& Di Giancamillo M. 2013. Serum biochemical response to contrast media administration in anesthetized dogs. Vet. Rec. 172(4):101-102.

Carraro-Eduardo J.C., Macedo H.W., Caldas M.L.R. \& Silva L.E. 2008. Nefropatia induzida por contraste: avaliação da proteção pela n-acetilcisteína e alopurinol em ratos uninefrectomizados. Radiol. Bras. 41(3):177181.

Choi J., Lee H., Chang D., Lee K., Choi K. \& Yoon J. 2001. Effect of dopamine on excretory urography image quality and the prevention of contrast induced nephropathy in dogs. J. Vet. Med. Sci. 63:383-388.

Del Vale A.M. 2011. Sumário de urina, p.93-106. In: Abensur H. (Ed.), Biomarcadores na Nefrologia. Roche, São Paulo.

Duan S.B., Wu H.W., Luo J.A. \& Liu F.Y. 1999. Assessment of renal function in the early stages of nephrotoxicity induced by iodinated contrast media. Nephron 83:122-125.

Engelhorn A.L., Carvalho J.G.R., Engelhorn C.A. \& Cassou M.F. 2006. Avaliação da perfusão renal pelo Power Doppler em pacientes transplantados renais. J. Vascular Bras. 5(2):109-116.

Goldstein R. 2011. Urinary enzyme activity for detection of acute kidney injury, p.70-72. In: Bartges J. \& Polzin D.J. (Eds), Nephrology and Urology of Small Animals. Wiley-Blackwell, Iowa.

Grauer G.F., Greco D.S., Behrend E.N., Mani I., Fettman M.J. \& Allen T.A. 1995. Estimation of quantitative enzymuria in dogs with gentamicin-induced nephrotoxicosis using enzyme/creatinine ratios from spot urine samples. J. Vet. Intern. Med. 9:324-327.

Grauer G.F. 2007. Measurement, interpretation, and implications of proteinuria and albuminuria. Vet. Clin. N. Am., Small Anim. Pactr. 37:283295.

Greco D.S., Turnwald G.H. \& Adams R. 1985. Urinary gamma-glutamyl transpeptidase activity in dogs with gentamicin-induced nephrotoxicity. Am. J. Vet. Res. 46:2332-2335.

Heyman S.N., Rosenberger C. \& Rosen S. 2005. Regional alterations in renal hemodinamycs and oxygenation: a role contrast medium-induced nephropathy. Nephrology Dialysis Transplantation 20:S06-11.

Hetzel G.R., May P., Hollenbeck M., Voiculesci A., Mödder U. \& Grabensee B. 2001. Assessment of radiocontrast media induced renal vasoconstriction by color coded duplex sonography. Ren. Fail. 23(1):77-83.

Hoyer P.F., Schmid R., Wünsch L. \& Vester U. 1999. Color Doppler energy: a new technique to study tissue perfusion in renal transplants. Pediatric Nephrol. 13:559-563.

Humes H.D., Hunt D.A. \& White M.D. 1987. Direct toxic effect of the radiocontrast agent diatrizoate on renal proximal tubule cells. Am. J. Physiol. 252:246-255.

Ihle S.L. \& Kostolich M. 1991. Acute renal failure associated with contrast medium administration in a dog. J. Am. Vet. Assoc. 199(7):899-901.

International Small Animal Cardiac Health Council 1999. Appendix A. Recommendations for diagnosis of heart disease and treatment of heart failure in small animals, p.883-901. In: Fox P.R., Sison D. \& Moïse N.S. (Eds), Textbook of Canine and Feline Cardiology. 2nd ed. W.B. Saunders Company, Philadelphia.

International Renal Interest Society. 2013. <http://www.iris-kidney. com/downloads/IRIS\%20GRADING\%200F\%20ACUTE\%20KIDNEY\%20INJURY\%20(final).pdf> Acessado em 14 set. 2013.

Janevski J. \& Moe G. 2003. Prevention of radiocontrast-induced nephropathy. Cardiology Rounds VIII, 6, june/july.

Jo S.H., Youn T.J., Koo B.K., Park J.S., Kang H.J., Cho Y.S., Chung W.Y., Joo G.W., Chae I.H., Choi D.J., Oh B.H., Lee M.M., Park Y.B. \& Kim H.S. 2006. Renal toxicity evaluation and comparison between visipaque (iodixanol) and hexabrix (ioxaglate) in patients with renal insufficiency undergoing cor- onary angiography: the recover study: a randomized controlled trial. J. Am. Coll. Cardiol. 48(5):924-30.

Juchem B.C., Dall'Agnol C.M. \& Magalhães A.M.M. 2004. Contraste iodado em tomografia computadorizada: prevenção de reações adversas. Revta Bras. Enfermagem 57(1):57-61.

Katholi R. 2006. Contrast-induced nephropaty: update and pratical clinical applications. US Cardiovascular Disease 3(2):73-80.

Katzberg R.W. 1997. Urography into the 21st century: new contrast media, renal handling, imaging characteristics and nephrotoxicity. Radiology 235:297-312.

Katzberg R.W. 2005. Contrast medium induced nephrotoxicity: which pathways? Radiology 235:752-755.

Kirberger R.M., Cassel N., Carstens A. \& Goddard A. 2012. The effects of repeated intravenous iohexol administration on renal function in healthy beagles - a preliminary report. Acta Vet. Scand. 54(47):1-11.

Kodaira S.K. 2002. Física, p.17-30. In: Cerri G.G. \& Oliveira I.R.S. (Eds), Ultra-sonografia Abdominal. Revinter, Rio de Janeiro.

Konde L.J., Wrigley R.H., Park R.D. \& Lebel J.L. 1984. Ultrasonographic anatomy of the normal canine kidney. Vet. Radiol. 25(4):173-178.

Kramer C.K., Leitão C.B., Canani L.H., Gross J.L. \& Silveiro S.P. 2008. Nefropatia induzida por contraste: medidas de prevenção. Revta Hosp. Clín. Porto Alegre 28:33-36.

Lees G.E. 2004. Early diagnosis of renal disease and renal failure. Vet. Clin. N. Am., Small Anim. Pract. 34:867-885.

Lees G.E., Brown J.E., Grauer G.F. \& Vaden S. 2005. Assessment and management of proteinuria in dogs and cats: 2004 ACVIM Forum consensus statement (Small Animal). J. Vet. Intern. Med. 19:377-385.

Lehmann E.L. \& D'abrera H.J.M. 2006. Nonparametrics statistical methods based on ranks. Springer, New York. 463p.

Lin L.A. 1989. Concordance correlation coefficient to evaluate reproducibility. Biometrics 45:255-268.

Loor J., Daminet S., Smets P., Maddens B. \& Meyer E. 2013. Urinary biomarkers for acute kidney injury in dogs. J. Vet. Intern. Med. 27:998-1010.

Love L. \& Harvey R. 2006. Arterial blood pressure measurement: physiology, tools and techniques. Compend. Contin. Educ. Pract. Vet. 28(6):450-458.

Martín C.M., Lorigados C.A.B., Kogika M.M., Miyashiro S.I., Sendyk-Grunkraut A., Zardo K.M. \& Fonseca-Pinto A.C.B.C. 2014. Contrast-induced nephropathy (CIN) in dogs: renal ultrasonography evaluation, p.840. Proc. World Small Animal Veterinary Association Annual Conference, Cape Town, South Africa, WSAVA, Cape Town.

Martín C.M., Souto C.K., Ferrante B. \& Fonseca-Pinto A.C.B.C. 2015. Ultrassonografia modo B e Doppler na avaliação renal de cães após administração intravenosa de meio de contraste iodado: validação da técnica. Pesq. Vet. Bras. 35(9):801-810.

McCullough P.A. 2008. Contrast-induced acute kidney injury. J. Am. Coll. Cardiol. 51(15):1419-1428.

Melo M.B., Veado J.C.C., Silva E.F., Moreira S.M. \& Passos L.M.F. 2006. Dopplerfluxometria das artérias renais: valores normais das velocidades sistólica e diastólica e do índice resistivo nas artérias renais principais. Arq. Bras. Med. Vet. Zootec. 58(4):691-693.

Morcos S.K. 1998. Contrast media-induced nephrotoxicity: questions and answers. J. Am. Soc. Nephrol. 11(7):177-182.

Morcos S.K. \& Thomsen H.S. 2001. Adverse reactions to iodinated contrast media. Eur. Radiol. 11:1267-1275.

Morrow K.L., Salman M.D., Lappin M.R. \& Wrigley R. 1996. Comparison of the resistive index to clinical parameters in dogs with renal disease. Vet. Radiol. Ultrasound 37:193-199.

Murakami R., Tajima H., Kumazaki T. \& Yamamoto K. 1998. Effect of iodixanol on renal function immediately after abdominal angiography: clinical comparison with iomeprol and ioxaglate. Acta Radiologica 39:368-371.

Murphy S.W., Barrett B.J. \& Parfrey P.S. 2000. Contrast nephropathy. J. Am. Soc. Nephrol. 11:177-182.

Novellas R., Espada Y. \& Gopegui R.R. 2007. Doppler ultrasonographic estimation of renal and ocular resistive and pulsatility indices in normal dogs and cats. Vet. Radiol. Ultrasound 48:69-73. 
Owens J.M. \& Biery D.N. 1998. Radiographic Interpretation for the Small Animal Clinician. Wiley, New York. 308p.

Platt J.F. 1992. Dupplex Doppler evaluation of native kidney dysfunction: obstructive and nonobstructive disease. Am. J. Roentgenol. 158(5): 1035-1046.

Pollard R.E., Puchalski S.M. \& Pascoe P.J. 2008a. Hemodynamic and serum biochemical alterations associated with intravenous administration of three types of contrast media in anesthetized dogs. Am. J. Vet. Res. 69(10):1268-1273.

Pollard R.E., Puchalski S.M. \& Pascoe P.J. 2008b. Hemodynamic and serum biochemical alterations associated with intravenous administration of three types of contrast media in anesthetized cats. Am. J. Vet. Res. 69(10):1274-1278.

Pollard R.E. \& Puchalski S.M. 2012. CT Contrast media and applications, p.57-66. In: Schwarz T. \& Saunders J. (Eds), Veterinary Computed Tomography. Willey-Blackwell, Iowa.

Pucelikova T., Dangas G. \& Mehran R. 2008. Contrast-induced nephropathy. Catheterization and Cardiovascular Interventions 71(1):62-72.

R CORE TEAM 2014. The R Project for Statistical Computing. Vienna <http://www.R-project.org/> Acessado em 31 ago. 2014.

Reddan D., Laville M. \& Garovic V.D. 2009. Contrast-induced nephropathy and its prevention: what do we really know from evidence-based findings? J. Nephrol. 22(3):333-351.

Ribeiro L., De Assunção E., Silva F., Kurihara R.S., Schor N., Mieko E. \& Higa S. 2004. Evaluation of the nitric oxide production in rat renal artery smooth muscle cells culture exposed to radiocontrast agents. Kidney International 65:589-596.

Rivers B.J., Walter P.A., Letourneau J.G., Finlay D.E., Ritenour E.R., King V.L., O'brien T.D. \& Polzin D.J. 1996a. Estimation of arcuate artery resistive index as a diagnostic tool for aminoglycoside-induced acute renal failure in dogs. Am. J. Vet. Res. 57:1536-1544.

Rivers B.J., Walter P.A., O’brien T.D., King V.L. \& Polzin D.J. 1996b. Evaluation of urine gamma-glutamyl transpeptidase-to-creatinine ratio as a diagnostic tool in an experimental model of aminoglycoside- induced acute renal failure in the dog. J. Am. Anim. Hosp. Assoc. 32:323-336.

Rodriguez D.M., Sarto C.G., Souza P.M., Zulim R.M.I. \& Mamprim M.J. 2013. Renal ultrasonographic evaluation in dogs after radiocontrast. Ultrasound in Medicine and Biology, Elsevier, Cincinnati, 39:S20.

Rudnick M.R., Goldfarb S. \& Wexler L. 1995. Nephrotoxicity of ionic and nonionic contrast media in 1196 patients: a randomized trial: the iohexol cooperative study. Kidney International 47:254-261.

Rudnick M.R., Palevsky P.M. \& Sheridan A.M. 2014. Prevention of contrast induce nephropathy (acute renal failure). UpToDate. <http://www.uptodate.com/contents/prevention-of-contrast-induced-nephropathy>. Acessado em 20 mar. 2014.

Sandler C.M. 2003. Contrast medium-induced acute renal dysfunction: is iodixanol the answer? New Engl. J. Med. 348(6):551-553.

Santin F., Amaral A.S. \& Takahira R.K. 2006. Acompanhamento laboratorial da função renal de cães sadios tratados experimentalmente com doses terapêuticas de anfotericina B. Ciência Rural 36(6):1816-1823.

Santos A.P., Gaivão A.M., Tavares A. \& Ferreira S. 2009. Produtos de contrastes iodados. Acta Médica Portuguesa 22(3):261-274.

Santos R.O., Malvar B., Silva R., Ramalho V., Pessegueiro P., Amoedo M., Aniceto J. \& Pires C. 2011. Nefropatia de contraste. Acta Médica Portuguesa. 24:809-820.

Schnell D. \& Darmon M. 2012. Renal Doppler to assess renal perfusion in the critically ill: a reappraisal. Intensive Care Med. 38:1751-1760.

Seeliger E., Sendeski M., Rihal C.S. \& Person P.B. 2012. Contrast-induced kidney injury: mechanisms, risk factors and prevention. Eur. Heart J. 33(16):2007-2015.

Seiler G.S. 2013. The kidneys and ureters, p.705-726. In: Thrall D.E. (Ed.),
Textbook of Veterinary Diagnostic Radiology. 6th ed. W.B. Saunders, St Louis, Missouri.

Shakourirad A., Ataeefar M. \& Jozagui S. 2009. Assessment of the effect of radio contrast media on resistive index of renal artery by color Doppler sonography. Saudi J. Kidney Dis. Transplant. 20:91-96.

Silva R.G., Silva N.G., Lucchesi F. \& Burdmann E.A. 2010. Prevenção de nefrotoxicidade por contraste com solução de bicarbonato - resultados preliminares e revisão da literatura. J. Bras. Nefrol. 32(3):292-302.

Stacul F. 2006. Late adverse reactions to intravascular iodinated contrast media, p.27-31. In: Thomsen H.S. (Ed.), Contrast Media: safety issues and ESUR guidelines. 2nd ed. Springer-Verlag, Berlin.

Stacul F. \& Bellin M.F. 2014. Late adverse reactions to iodine-based contrast media, p.141-146. In: Thomsen H.S. \& Webb J.A.W. (Eds), Contrast Media: safety issues and ESUR guidelines. 3rd ed. Springer-Verlag, Berlin.

Szatmári V., Sótonyi P. \& Vörös K. 2001. Normal duplex Doppler waveforms of major abdominal blood vessels in dogs: a review. Vet. Radiol. Ultrasound 42:93-107.

Thadhani R., Pascual M. \& Bonventre J.V. 1996. Acute renal failure. New Engl. J. Med. 334(22):1448-146.

Thomsen H.S. 2003. Guidelines for contrast media from the European Society of Urogenital Radiology. Am. J. Roentgenol. 181(6):1463-1471.

Thomsen H.S. 2006. Reducing the risk of contrast medium induced nephropathy, p.35-45. In: Thomsen H.S. (Ed.), Contrast Media: safety issues and ESUR guidelines. Springer, New York.

Thomsen H.S. 2011. Contrast media safety: an update. Eur. J. Radiol. 80(1): 77-82.

Thomsen H.S. \& Morcos S.K. 2000. Radiographic contrast media. Brit. J. Urology Int. 86:S1-10.

Thomsen H.S., Morcos S.K. \& Barrett B.J. 2008. Contrast-induced nephropathy: the wheel has turned 360 degrees. Acta Radiologica 49:646-657.

Thomsen H.S., Stacull F. \& Webb J.A.W. 2014a. Contrast medium-induced nephropathy, p.81-104. In: Thomsen H.S. \& Webb J.A.W. (Eds), Contrast Media: safety issues and ESUR guidelines. 3rd ed. Springer, New York.

Thomsen H.S., Bellin M.F., Jakobsen J.A. \& Webb J.A.W. 2014b. Contrast media classification and terminology, p.3-16. In: Thomsen H.S. \& Webb J.A.W. (Eds), Contrast Media: safety issues and ESUR guidelines. 3rd ed. Springer, New York.

Toprak 0. 2007. Conflicting and new risk factors for contrast induced nephropathy. J. Urol. 178(6):2277-2283.

Trhall M.A., Baker D.C. \& Campbell T.W. 2007. Hematologia e Bioquímica Clínica Veterinária. Roca, São Paulo. 592p.

Tripathy N.K., Gregory C.R. \& Latimer K.S. 2011. Urinary system. In: Latimer K.S. (Ed.), Duncan \& Prasses's Veterinary Laboratory Medicine: clinical pathology. 5th ed. Willey-Blackwell, Iowa.

Ultramari F.T., Bueno R.R.L., Cunha C.L.P., Andrade P.M.P.A., Nercolini D.C., Tarastchuk J.C.E., Faidiga A.M., Melnik G. \& Guérios E.E. 2006. Nefropatia induzida pelos meios de contraste radiológico após cateterismo cardíaco diagnóstico e terapêutico. Arqs Bras. Cardiol. 87(3):378-390.

Vianna P.T.G. 2006. Marcadores biomoleculares da insuficiência renal. In: Cavalcante I.L., Cantinho F.A.F. \& Assad A. (Eds), Medicina Perioperatória. Sociedade de Anestesiologia do Estado do Rio de Janeiro, Rio de Janeiro.

Walter P.A., Johnston G.R., Feeney D.A. \& O’Brien T.D. 1987. Renal ultrasonography in healthy cats. Am. J. Vet. Res. 48(4):600-607.

Wickham H. 2009. ggplot2: elegant graphics for data analysis. 3rd ed. Springer, New York.

Widmark J.M. 2007. Imaging-related medications: a class overview. Proc. Baylor University Medical Center 20:408-417.

Wong G.T.C. \& Irwin M.G. 2007. Contrast-induced nephropathy. Brit. J. Anaesthesia 99(4):474-483. 